ISSN: 0213-2079 - ISSN electrónico: 2386-3889

DOI: https://doi.org/10.14201/shhmo2017392257291

\title{
ALIVIAR A LOS VECINOS: EL CONSEJO DE CASTILLA Y LAS OBRAS PÚBLICAS EN EL REINADO DE CARLOS II. PUENTES Y VECINOS
}

\section{Relieving Neighbours: The Council of Castile and Public Works during Carlos II Kingdom. Bridges and Neighbours}

\author{
Jesús BRAVO LOZANO
}

Universidad Autónoma de Madrid

Correo-e: jesus.siro@gmail.com

RESUMEN: Las necesidades de los intercambios comerciales entre los puertos del Cantábrico, Castilla, la Corte y Cádiz obligan a mantener abiertos los puentes, grandes y pequeños. El costo de las obras recae sobre poblaciones generalmente pobres, lo que provoca innúmeros problemas y protestas. Todo ello en el marco de la década final del siglo xvII, especialmente adversa, por lo que el Consejo de Castilla intenta equilibrar los elevados costos repartiéndolos equitativamente entre los vecinos. Ello obliga a hacer continuos recuentos de vecinos en las zonas afectadas.

Palabras clave: Fines del siglo xvir; Climatología; Consejo de Castilla; Puentes; Vecinos; León; Protestas; Administración.

ABSTRACT: The needs of trade between ports of the Cantabrian Sea, Castilla, the Court and Cádiz obliged to maintain open bridges, large and small ones. The cost of the works falls on usually poor villages, causing countless problems and protests. All this within the framework of the Decade at the end of the 17th century, particularly adverse, so the Council of Castile tries to balance high costs by distributing them evenly among the neighbours. This forces to make continuous counts of residents in affected areas. 
JESÚS BRAVO LOZANO

ALIVIAR A LOS VECINOS: EL CONSEJO DE CASTILLA Y LAS OBRAS PÚBLICAS EN EL REINADO DE CARLOS II. PUENTES Y VECINOS

Key words: End of 18th Century; Climatology; Council of Castile; Bridges; Neighbours; León; Protests; Administration.

\section{INTRODUCCIÓN}

Con este trabajo se pretende hacer una reflexión sobre dos cuestiones planteadas en distintos momentos. Por un lado, la definición de las obras públicas en el xvir como un gravamen oneroso y desconocido por los historiadores y, por otro, los intentos de Carlos II y sus Consejos de aliviar la carga fiscal de sus súbditos ${ }^{1}$. No es el objetivo saber cuál de las dos posturas es más realista. En términos documentales ambas vienen respaldadas por numerosos textos administrativos. Pero no se trata de hacer una cremallera de textos. Sánchez Belén ${ }^{2}$ en sus sólidos estudios sobre la fiscalidad de Carlos II, mantiene la tesis del «alivio de los vasallos» a través de sucesivas medidas de perdón de atrasos, devaluaciones, intentos de recuperar mercedes indebidas, etc., vinculándolo todo ello no a cuestiones meramente pragmáticas, sino a un propósito político de traducir en medidas concretas las tesis arbitristas ${ }^{3}$. Cecilia Pont de Villanueva asume el punto de vista de Sánchez Belén. Reconoce que la política fiscal en aquellos momentos hubo de centrarse más en medidas concretas que en rebajas de impuestos ${ }^{4}$. Simplificando: gravamen oneroso que un bien informado Consejo de Castilla procura mitigar.

Sobre las obras públicas sigue siendo indispensable la obra de Alzola Minondo, por su información y diversidad de fuentes, aunque cubre escasamente nuestro tema y está escorada hacia una tesis claramente política: los Austrias derivaron sus inmensos caudales a una política exterior nefasta, mientras Francia promocionó las

1. Vela Santamaría, F. J.: «Las obras públicas en la Castilla del siglo xvir: un gravamen oneroso y desconocido», Stvdia Historica. Historia Moderna, 32, 2010, pp. 125-177.

2. Sánchez Belén, J. A.: La política fiscal en Castilla durante el reinado de Carlos II. Madrid, 1996. Ver cap. 4. SÁnChEZ Belén, J. A.: «Absolutismo y fiscalidad en Castilla a finales del s. xviI: el empadronamiento general del Reino (1682-1685)», Espacio, Tiempo y Forma. Serie IV, Historia Moderna, 2, 1989, pp. 175-218.

3. Así lo confirma la «Junta particular sobre moneda y otros medios», Archivo Histórico Nacional [en adelante AHN], Consejos, libro 51.360 expedientes 65 y 77, que estudia la política monetaria en torno a la devaluación de febrero de 1.680. En: BRAvo LozANO, J.: «La devaluación de 1.680. Propuesta de análisis», Hispania, LIII, 1993, pp. 115-146.

4. Font de Villanueva, C.: «Política monetaria y política fiscal en el siglo Xvir: un siglo de inestabilidad», Revista de Historia Económica, XXIII:1, 2005, p. 345, nota 31, refuerza su posición con este comentario: «Un estudio de Andrés Ucendo demuestra cómo la recaudación fiscal por concepto de millones, cientos y alcabalas descendió sustancialmente a partir de 1.682».

Ediciones Universidad de Salamanca / 요 Stud. his., H. ${ }^{a}$ mod., 39, n. 2 (2017), pp. 257-291 
grandes obras públicas. Añádase que en España el control de los Consejos impidió la iniciativa de las comunidades, y donde esta existió, como en las Provincias Vascongadas y en Navarra, florecieron las obras públicas ${ }^{5}$. Por su parte Aramburu Zabala concluye su estudio sobre la centralización de las comunicaciones en torno a Madrid señalando «la injusticia históriográfica que supone dejar en el vacío la construcción de obras públicas durante los siglos XVI y XVII» ${ }^{6}$.

El tema puentes ya mereció la atención de historiadores de Historia del Arte al estudiar la conexión entre una corte que se asentó definitivamente en Madrid y el complejo político-religioso del monasterio de S. Lorenzo del Escorial. Los puentes facilitaban tal conexión. Recordemos los trabajos de Navascués, Agustín García Bustamante y otros ${ }^{7}$. Las jornadas reales reforzaban la identificación entre rey y territorio ${ }^{8}$. Aramburu-Zabala dio un giro a estos estudios centrándose en las técnicas y los maestros canteros montañeses ${ }^{9}$. Vela Santamaría le ha dado el

5. Alzola Minondo, P.: Historia de las Obras Públicas en España. Madrid, 2001, 3. ed. Se ha manejado la primera de 1.979, pues las siguientes no añaden nueva información.

6. Aramburu-Zabala higuera, M. Á.: «Todos los caminos conducen a Madrid. Los primeros pasos de la centralización de las comunicaciones españolas», en Madrid en el contexto de lo bispánico desde la época de los descubrimientos, 1994, t. 2, p. 797.

7. Bustamante García, A.: «Caminos y Palacios. Felipe II entre la Capital y el Escorial», en Madrid en el contexto de lo hispánico desde la época de los descubrimientos, 1994, t. I, pp. 23-29. Hay otros estudios sobre puentes particulares atribuidos a Juan de Herrera, Cervera VerA, L.: «Juan de Vera diseña el puente sobre el río Guadarrama», Anales del Instituto de Estudios Madrileños, XXII, 1985, pp. 65-80. Miguel CuestA, A.: «Puente nuevo sobre el río Guadarrama en Galapagar», Anales del Instituto de Estudios Madrileños, XXV, 1988, pp. 477-482, informando sobre un proyecto de 1582. Navascués, P.: «Puentes de acceso al Escorial», Archivo Español de Arte, LVIII, 1985, pp. 97-107. Anteriormente Pedro Navascués decía: «No conozco cuándo se llevó a cabo el puente de Retamar, pero por su estilo creo que puede pertenecer al siglo xvII, y sería para mí un buen ejemplo de puente de la época de los Austrias... parece posterior a los puentes proyectados por Gómez de la Mora...».

8. EzQuerra Revilla, I.: Jornadas reales, red viaria y continuidad territorial de la Corte: las prevenciones camineras del doctor Juan de Quiñones, alcalde de casa y corte. Libros de la Corte.es (3) 2011. Además subraya la identificación entre territorio en general y rey por lo que la corona ejerce funciones de fomento tanto como de justicia en todo el territorio. EzQUERRA Revilla, I. J.: «Los sitios reales y la continuidad territorial de la Corte. El espacio patrimonial real y su integración en el entorno», en Martínez Millán, J. y Hortal Muñoz, J. E. (coords.): La Corte de Felipe IV (1621-1665). Reconfiguración de la Monarquía Católica. Madrid, 2015, vol. 3, pp. 2047-2149.

9. Aramburu-Zabala Higuera, M. A.: Las obras públicas en la Corona de Castilla entre 1575 y 1650. Los puentes. Tesis doctoral defendida en la Universidad Autónoma de Madrid en 1987. Microficha, 1990; del mismo autor: La arquitectura de puentes en Castilla y León, 1575-1650. Valladolid, 1992. Aramburu-Zabala recalca, además, el papel de la corrupción generalizada en las obras públicas. Aramburu-Zabala Higuera, M. A.: Fraude y corrupción en la arquitectura del siglo de oro. Universidad de Cantabria, 2001.

Ediciones Universidad de Salamanca / 요 Stud. his., H. ${ }^{a}$ mod., 39, n. 2 (2017), pp. 257-291 
enfoque ya expuesto: gravamen oneroso. Ambos detienen sus investigaciones a la altura de 1650.

La fuente básica que manejan es el Registro General del Sello del Archivo General de Simancas, parte de cuyos fondos, los que arrancan de enero de 1690, han sido depositados en el Archivo Histórico Nacional ${ }^{10}$. Ello me ha permitido su consulta sistemática siguiendo sus pasos. En efecto, los problemas que ambos tratan se repiten en los años que median entre 1690 y 1700 (años de mi consulta) dado que entre 1650 - 1690 no hay avances técnicos significativos. Así que especificaciones técnicas como las que se transcriben para las reparaciones del puente de Alba de Tormes ${ }^{11}$, o Quintana del Puente responden a unas prácticas conocidas y dominadas «es condición que el maestro en quien se rematare dicha obra haya de poner al pie della todos los materiales necesarios de piedra y madera, cal y arena mezclando y batiendo y repasando los morteros dos meses antes que se hayan de gastar...» "para seguir precisando que se han de cimbrear los dos arcos dañados y demolerlos con todo cuidado para evitar desgracias, se ha de demoler la cepa en que se apoyan dichos arcos. Viene luego el profundizar hasta que aparezca una base sólida de tierra firme, peña o greda o cascaja. Si esto no sucede, hay que seguir profundizando al menos 8 pies "de la superficie de la tierra" para hacer una plataforma artificial de 48 por 18 pies utilizando barras de hierro para calar, estacas de roble o aliso o enebro, aparte del relleno y encofrado necesario de estacas y vigas, más piedra y casquillos y puntas de hierro» ${ }^{12}$.

\section{Climatología y puentes}

Estamos en la «pequeña edad del hielo» ${ }^{13}$, caracterizada por la «variabilidad, irregularidad y extremismos... fuertes precipitaciones de alta intensidad horaria

10. Sobre el Registro General del Sello, ver: Álvarez-Coca GonzÁlez, M. ${ }^{a}$ J.: «La Cámara de Castilla: secretaría de Gracia y Justicia. Problemas archivísticos e investigación histórica», en ScHolz, J-M.: El tercer poder: hacia una comprensión histórica de la Justicia contemporánea en España, Fráncfort del Meno, 1992, pp. 1-32. También: Álvarez-Coca GonzÁlez, M. J. (dir.) et al.: La Cámara de Castilla: Inventario de los libros de la Secretaria de Gracia y Justicia que se conservan en el Archivo Histórico Nacional. Madrid, 1993. Existe una reedición reciente. Las posibilidades del Registro General del Sello vienen dadas por Marcos MarTín, A. (ed.): Hacer Historia desde Simancas. Homenaje a José Luis Rodríguez de Diego. Valladolid, 2011.

11. AHN, Registro General del Sello [en adelante RGS], leg. 7.537, 10 de marzo de 1690; leg. 7.544, 27 de junio de 1691 y leg. 7.547, 24 de diciembre de 1691.

12. AHN, RGS, leg. 7.574, 6 de mayo de 1694. Las técnicas de construcción de los puentes están bien estudiadas por: GARCía TAPIA, N.: Técnica y poder en Castilla durante los siglos XVI $y$ XVII. Salamanca, 1989, p. 40 estudia los puentes de la cuenca del Duero.

13. Alberola, A.: Los cambios climáticos. La Pequeña Edad del Hielo en España. Madrid, 2014.

Ediciones Universidad de Salamanca / 요 Stud. his., H. ${ }^{a}$ mod., 39, n. 2 (2017), pp. 257-291 
seguidas de riadas e inundaciones... -y en el siglo XvII- predominio de acontecimientos hidrometereológicos de rango extraordinario y signo extremo» ${ }^{14}$. Vela Santamaría ofrece datos sistemáticos para el espacio centro-norte en los años 1620/30. Sabemos, por tanto, que muchos de los puentes de los que tratamos en este trabajo han sufrido lluvias torrenciales 60 años atrás. En 1626, «el año del diluvio», el río Carrión daña el puente de Saldaña que volverá a verse afectado en 1642 y 1643; en 1636 hay riadas que afectan Covarrubias, en 1638 le toca el turno a Lerma y en 1649 Quintana del Puente ${ }^{15}$. Para finales de siglo Juan de la Lastra Ortiz, maestro de cantería de Cudeyo, informa que las riadas de octubre de 1689 han derruido puentes antiguos y sólidos en Saldaña, Guardo, Villarente, así como otros muchos de madera, uno en Boca de Huérgano, otro en Pedrosa ${ }^{16}$.

En junio de 1692, se ordena al corregidor del Principado de Asturias girar una inspección a diversos concejos, en especial el de Infiesto, para estudiar y solucionar los daños causados por las lluvias torrenciales de agosto del año 1691 que han arrastrado más de 16 puentes en todo el Principado ${ }^{17}$. Todavía en 1694 se comisiona a un delegado del Principado para que exponga en la corte la desastrosa situación en que ha quedado el Principado después de 5 años de malas cosechas «y ruynas de todas sus puentes, molinos y caminos con la inundación de 1691» ${ }^{18}$. Finalmente, el invierno de 1694/95 fue muy frío y lluvioso.

\section{Puente y Puentes}

Hay puentes más próximos a la corte, identificables fácilmente como espacios cortesanos. El Consejo agiliza todos los trámites en estos casos, a diferencia de lo

14. Alberola, A.: op. cit., p. 92 y ss.

15. Vela Santamaría, F. J.: «Una fuente inédita para la demografía de la Corona de Castilla en el siglo XVI: El Registro General del Sello", en Marcos MarTín, A. (ed.): Hacer Historia desde Simancas. Homenaje a José Luis Rodríguez de Diego. Valladolid, 2011, pp. 819-820, con la enumeración de las riadas de 1637-1640. Para la riada de 1626 en Sevilla recogida en la página 821, nota 63, se puede leer la vívida descripción que recoge el inquisidor Fr. D. Juan Dionisio Fdez. Portocarrero, AHN, Inquisición, L ${ }^{\circ} 2046$, carta del 17 de febrero de 1626. Ver también Biblioteca Nacional [en adelante BN], mss. 1713: Relación de la inundación de Sevilla del año 1626 del Ldo. Rodrigo Caro a don Francisco de Quevedo, con fecha de 10 de febrero. Alberola le dedica algunas páginas específicas a esta riada y a la del Tormes. Alberola, A.: op. cit., pp. 159-162.

16. AHN, RGS, leg. 7.541, 22 de noviembre de 1690.

17. Idem, leg. $7.554,30$ de junio de 1692. Según Alberola: op. cit., p. 176 en Asturias hay «excesos hídricos» en el bienio 1693-1694, creo más fiable la información del Consejo. En las mismas páginas Alberola recoge una riada en Valladolid del Esgueva y el Pisuerga en 1692, pero nada sobre otras inundaciones que afectan a nuestros puentes.

18. Idem, leg. 7.590, 27 de febrero de 1697. 
que hace con otros puentes. Así sucede en la construcción de un puente sobre el Guadarrama en el camino entre Las Rozas y Colmenarejo para facilitar la jornada del rey al Escorial ${ }^{19}$. El 19 de junio 1691, el Consejo ordena al teniente de corregidor de Madrid iniciar los preparativos para realizar con urgencia el referido puente. El razonamiento es claro. La jornada del rey al Escorial es muy costosa para los pueblos obligados a mantener en buen estado los caminos, así que construir un puente en el lugar escogido, evitando la subida hasta Torrelodones, tendría la doble ventaja de acortar la duración del viaje real y liberar a los campesinos del trabajo anual en los caminos; a cambio de esta ventaja, «alivio» dice el texto, no se duda de que los campesinos aceptarían una pequeña contribución para las obras del puente. El costo se calcula en 8 o 9.000 ducados que se financiarán fácilmente repartiendo 70.000 reales entre los pueblos situados en un área de 10 leguas y fabricando, primero, un molino harinero, tal como se ha hecho en Tordesillas y otras partes y, también, una venta para su explotación por particulares, que ya han mostrado su disponibilidad para participar.

La diferencia entre el puente del Guadarrama y los demás radica en que el del Guadarrama es un «puente de corte», lo que entendemos como «real sitio» ${ }^{20}$. Iniciativa de la Corte que agiliza gestiones de todo tipo evitando interferencias de intereses encontrados, tal como Vela Santamaría pone de manifiesto para las obras del puente de Castro Gonzalo en Benavente ${ }^{21}$, o lo que sucede con el puente sobre el río Nalón en el Principado de Asturias, donde el Consejo ordena la fabricación del puente solicitado por el Principado, revocando la sentencia de la Real Chancillería de Valladolid a favor de D. Sebastián Bernaldo de Quirós y Benavides, señor de Olloniego, propietario de una barca sobre el río ${ }^{22}$.

19. AHN, RGS, leg. $7.544,19$ de junio de 1692. Ver: Corella SuÁrez, P.: «Puentes y caminos reales en torno a la corte, siglos XVII y XVIII», en Madrid en el contexto de lo hispánico desde la época de los descubrimientos, 1994, t. 1, pp. 63-66. En 1.577 un tal Alonso de Sotomayor se ahoga en el río Guadarrama camino del Escorial. Alzola Minondo: op. cit., p. 180.

20. IULCE. Congreso Internacional: «La Extensión de la Corte: los Sitios Reales». Madrid, Universidad Rey Juan Carlos I y Universidad Autónoma de Madrid, 14-16 noviembre 2012. Entre los objetivos, cito: «se pretendía comprobar la relevancia de estos Sitios reales en la construcción, definición y devenir de la Monarquía», donde los Sitios Reales jugaban un papel fundamental «para extender la imagen que el monarca quería a lo largo de todo el reino». Aunque esto último se refiere especialmente a confesionalización, es aplicable a cualquier otro aspecto. Así que, un puente, adquiría la categoría especial de elemento físico, recordatorio de la imagen del Rey. Este planteamiento difiere del de otros estudios, como el de José M. ${ }^{a}$ López García en su monografía sobre el influjo de la corte en la corona de Castilla. López García, J. M. (dir.): El impacto de la Corte en Castilla: Madrid y su territorio en la época moderna. Madrid, 1998. Ver Ezquerra Revilla, I. J., nota 8.

21. Vela Santamaría, F. J.: «Las obras públicas....», op. cit., pp. 170-173.

22. AHN. RGS, leg. 7.557, 2 de octubre de 1692. 


\subsection{Los «otros» puentes (casi todos)}

Preocupa la comunicación regular y segura entre los puertos del Cantábrico y la corte ${ }^{23}$, entre Galicia y la Corte, y la comunicación transversal. Leyendo los documentos relativos a la reparación de puentes uno podría imaginar a los labriegos castellanos inmersos en una economía de mercado e intercambios. Siempre se alega que tal o cual puente son importantes porque por ahí llegan las mercancías de Vizcaya, de los puertos del Cantábrico hacia Castilla y la Corte. A veces se precisa más, tal puente une Burgos y Castilla, tal otro Galicia, León y Valladolid, en algunos casos se especifica la conexión entre el Cantábrico, la Corte y Cádiz, etc.

La documentación manejada da cuenta, en especial, de intereses comerciales de villas y ciudades, pero no de los campesinos y de los pueblos, ¿están estos campesinos castellanos, en cuyo nombre se solicitan las reparaciones, interesados en las obras de reparación? Hay multiplicidad de respuestas. Saldaña se tiene por «una de las más principales villas del Reyno» y solicita la reconstrucción del puente sobre el río Carrión arruinado el invierno pasado, que es paso para la Corte, Peñaranda, Río Seco (Medina), Villada y las ferias y mercados de «Sahún» (Sahagún) y los reinos de Castilla la Vieja, montaña de León, Burgos y puertos de Santander, Bilbao y San Vicente de la Barquera ${ }^{24}$. Lerma precisa todavía más. Por los puentes que pretende reconstruir «se conducían y passava todo género de pescado, fierro, lana, vino y otros géneros de mercaderías» ${ }^{25}$.

¿Han sopesado los concejos rurales las ventajas de asegurar y agilizar el tránsito de mercancías y pasajeros comparándolas con el costo de las obras y las repercusiones económicas sobre sus haciendas? Téngase en cuenta que la localidad donde se hacía la obra computaba por el doble de vecinos, es decir, a cada vecino se le repartía doble cantidad que a los del resto de las 20 leguas $^{26}$. Los pueblos hacen valer su propio interés local aunque saben integrarlo en un interés general. La respuesta de Cervatos de la Cueza, similar a la de Saldaña, es que necesita reconstruir los puentes que le comunican con la feria de Villada y con los puertos del Cantábrico de donde reciben el pescado.

23. Lucas Villanueva, O.: «El transporte terrestre a través de la cordillera cantábrica en tiempos de Felipe II. Un estudio a partir de la correspondencia de Simón Ruiz con Laredo», Studia Historica. Historia Moderna, 34, 2012, pp. 257-281.

24. AHN, RGS, leg. 7.536, 12 de abril de 1690.

25. AHN, RGS, leg. 7.556, 4 de julio de 1693.

26. Vela Santamaría recuerda que legalmente el porcentaje era de la cuarta parte de la obra, pero que podía rebajarse hasta la décima parte. Vela SAntamaría, J.: «Las obras públicas...», op. cit., p. 159. 
El Consejo procura discernir las demandas de los pueblos y en ocasiones muestra un notable escepticismo. Nada nuevo. Un memorial presentado a las Cortes el 22 de febrero de 1622 afirmaba que la mayor parte de las obras de puentes eran innecesarias, y que respondían a intereses particulares de vecinos poderosos, intereses de los receptores y depositarios de los fondos, incluso de los jueces encargados de la administración, sin olvidar los provechos de jueces y escribanos $^{27}$. Ante la petición de un puente por parte de Sta. María de la Hoz, de Cayón, reconoce que en muchas ocasiones los pueblos «quieren autorizarse con un puente» ${ }^{28}$. Similar sería el caso de Villasur de los Herreros, que pide cobrar peaje en el puente sobre el Arlanzón, construido a sus expensas, y declararlo "puente real» ${ }^{29}$. En esa función de discernimiento tiene un papel básico el fiscal que debe informar todas las peticiones desde un punto de vista político y económico. Cuando el Consejo ordena un nuevo pregón de obras o el repartimiento definitivo lo hace con esta frase estereotipada: «oído lo que el fiscal dijo». ¿Qué les aporta a los campesinos las reparaciones del puente de S. Marcos planificado para facilitar el comercio con Galicia y Asturias? ${ }^{30}$. El fiscal no lo formula en estos términos, pero a eso responde su intervención en el proceso administrativo de la concesión de licencia para proceder al repartimiento. En resumen, el Consejo Real regula las comunicaciones en beneficio de intereses generales de los vasallos, aunque estos se resisten a pagar una obra que necesitan.

\section{Protesta y Resistencias}

En septiembre de 1680 una riada destruye totalmente el puente de Toledo de la villa de Madrid e inmediatamente se planifica su reconstrucción, dando origen al actual, pensado como un puente de «corte» pues el repartimiento se hace entre los «reinos» del Sur del sistema central y no solo entre las localidades situadas en 20 leguas a la redonda. El costo se establece en 120.000 ducados, la cuarta parte a cargo de la villa de Madrid, repartiéndose los 90.000 restantes entre

27. Aramburu-Zabala, M. A.: Fraude y corrupción en la arquitectura del siglo de Oro, p. 40 y $43-44$.

28. AHN, RGS, leg. 7.554, 14 de julio de 1692. «Muchos pueblos» dice el Consejo. Hasta el año 1696 (puente de León) hay más de 90 referencias a puentes en el RGS, y no he contabilizado los años siguientes.

29. AHN, RGS, leg. 7.543, 30 de abril de 1690 y leg. 7.549, 29 de febrero de 1692.

30. Ver Bartolomé Bartolomé, J. M.: «Condiciones de vida y privacidad cotidiana del campesinado leonés de Tierra de Campos: la comarca de Sahagún en el siglo XviI», Estudios Humanísticos, Historia, 3, 2004, pp. 37-51, analiza un ambiente de pobreza generalizada, ver p. e. p. 46 , nota 3. 
Toledo (16.000), Córdoba (14.000), Jaén (12.000) Murcia (12.000), Sevilla (20.000) y Granada (16.000). El Registro General del Sello da cuenta de las resistencias y protestas de Talavera, Córdoba, Illescas (requerida en tres ocasiones a pagar lo que le corresponde) y Murcia, requerida en dos ocasiones ${ }^{31}$. No se expresa el motivo de las protestas, pero no tendrían nada que ver con el fraude protagonizado por el maestro de obras que, al mismo tiempo que el puente, está edificando en Puerta Cerrada el palacio del conde de Medellín, cargando al puente todo el costo de la piedra que trae para las obras del palacio ${ }^{32}$.

La protesta y la resistencia, no a la obra sino al pago, está generalizada y sigue las mismas pautas. Mayoritariamente los pueblos se aferran a requisitos legales, como la distancia. El pueblo en cuestión -se alega- no está comprendido en las 20 leguas del repartimiento. En numerosas ocasiones se hacen valer privilegios o exenciones de contribuir a las obras de puentes y calzadas. Muchos pueblos han comprado tales exenciones. Medina del Campo había obtenido en 1646 la exención por 50 años haciendo un donativo de 500 ducados, caducaba en 1696 pero se le renovó por otros 50 años ${ }^{33}$.

Siguen las motivaciones socioeconómicas: el pueblo no tiene propios, o, caso de retranca lugareña, no es ese pueblo sino otro, como dice la autoridad de Zahara en el reino de Sevilla, cuando le reclaman la contribución para el puente de Toledo: el pueblo no es Zahara, como se dice en el repartimiento, sino «Zagara» ${ }^{34}$.

La asignación de vecinos a la localidad es otro motivo de protesta. Reinosa en 1696 alega que se le ha hecho el repartimiento para el puente de Cervera contabilizando 300 vecinos, siendo así que desde hace 14 años solo «computa»114 35 .

Con frecuencia se conceden exenciones motivadas en la buena labor de los pueblos. Al valle de Sedano se le exime de la contribución a los puentes próximos porque sus 25 lugares y un barrio han gastado en 50 años 100.000 ducados en

31. AHN, RGS, leg. 7. 538-I, 14 de junio de 1690 para Talavera; leg. 7.538-II, 29 mayo 1690 para Córdoba; leg. 7.538-II- 31 de mayo de 1690, Illescas y también leg. 7.539, 13 de agosto de 1690 y leg. 7.540, 20 de noviembre 1690; leg. 7.539, 17 de agosto de 1690, Murcia y también: leg. $7.540,8$ de noviembre de 1690. Estas referencias no son exhaustivas. De momento el puente no se construyó, hubo que esperar nuevos proyectos en el s. XVIII. Verdú RuIz, M: «El puente de Toledo: un hito brillante en la aportación del arquitecto Pedro de Ribera», Anales del Instituto de Estudios Madrileños, T. XXXIII, 1993, p. 56.

32. Pescador del Hoyo, M. ${ }^{a}$ C.: "Fraude en el Puente de Toledo, 1673-1680». Anales del Instituto de Estudios Madrileños, 6, 1970, pp. 85-113, pp. 96 y ss.

33. AHN, RGS, leg. 7.589, 29 de noviembre de 1696. La información procede de la reclamación que hace Medina por haber sido obligada a contribuir al puente de S. Julián de Arévalo por las presiones de Arévalo y Segovia y su tierra.

34. AHN, RGS, leg. 7.538-1, 3 de junio de 1690.

35. AHN, RGS, leg. 7.584, 26 de enero de 1696. 
mantener 5 puentes de piedra, uno de ellos sobre el Ebro, y 20 de madera con sus respectivas calzadas, y están construyendo uno nuevo. Gracias a esas obras están en contacto con los puertos del Cantábrico y las ciudades de las dos Castillas ${ }^{36}$.

\subsection{Protesta extrema: San vicente de la Barquera}

En San Vicente de la Barquera la reclamación se transforma en resistencia violenta, a lo que el Consejo debe dar otro tipo de respuesta. Todo transcurre entre octubre de 1691 y octubre de $1693^{37}$. En 24 de abril de este último año se ordena al corregidor de las Cuatro Villas de la mar trasladarse a San Vicente de la Barquera y convocar concejo abierto para tratar la difícil situación de la villa necesitada de pronto remedio: malas cosechas de los últimos diez años y la falta de pesca, todo ello en una villa que es «frontera» y debe mantenerse en armas. Están debiendo a la Real Hacienda hasta 50.000 reales. Tienen 3 puentes que atender: el de la Maza, con 32 arcos todos de piedra; el del Peral con un arco de piedra y lo demás de madera fundado sobre tres pilares de piedra y el de entrambos ríos, de madera fundada sobre postes y pilares de piedra, los tres bañados por el mar y sus mareas. Son puentes necesarios para el comercio con Asturias, Galicia y Vizcaya, etc. y llevan gastados hasta 4.000 ducados en mantenerlos. Además, deben contribuir al mantenimiento de los puentes de Pedrosa y Castañeda. Para mayor calamidad, el tres de enero de este año al mediodía cayó una centella sobre la iglesia derribando la torre y la cúpula de media naranja.

Con este trasfondo, en 1691 la villa no solo se niega a pagar los 118.000 maravedíes que se le han repartido para el puente de Matamorosa en Frías, que les reclama Emeterio de la Sota, comisionado por el Consejo para el cobro, sino que amenazan con darle muerte, apedreando su posada en varias ocasiones y escribiendo libelos amenazantes de tal manera que Emeterio de la Sota hubo de abandonar la villa. Hay repetidas órdenes del Consejo al corregidor de las Cuatro Villas de la mar residente en Laredo, para que se desplace a San Vicente de la Barquera y actúe con toda energía en el caso, en junio de 1692 y todavía en 25 y 26 de octubre de 1693. Deberá abrir una información exhaustiva de los hechos y personas implicadas en ellos: alcaldes ordinarios, regidores, procurador general de la villa y mayordomo

36. AHN, RGS, leg. 7.562, 13 de marzo de 1693. La concesión es fruto de la visita del corregidor de Reinosa comisionado por el Consejo en 10 de setiembre de 1692, AHN, RGS, leg. 7.557, 13 octubre 1692 .

37. AHN, RGS, leg. 7.546, 25 de octubre de 1691; leg. 7.553, 4 de junio de 1692 y leg. 7.563, 24 de abril de 1693 . Vela Santamaría recoge obras en estos puentes «hazerlas todas de piedra» con un costo de 23.500 ducados ya en 1608, op. cit., p. 149, nota 36 .

Ediciones Universidad de Salamanca / 요 Stud. his., H. ${ }^{a}$ mod., 39, n. 2 (2017), pp. 257-291 
del cabildo de mareantes y proceder judicialmente tipificando los hechos denunciados, juzgarlos, dictar sentencias y establecer las penas correspondientes. Deberá, asimismo, cobrar los 118.000 maravedíes, más los costos de los 29 días que dura la comisión de Emeterio de la Sota. Se le faculta para hacer prisiones, embargos, ventas y remates de bienes. Además, deberá multar con 50 ducados (y cobrar) a cada uno de los dos alcaldes y con 25 a cada uno de los regidores.

\section{GRAVAMEN ONEROSO}

Resistencias y protestas ante un gravamen oneroso. Con paciencia, tiempo e informática se podría sopesar cuánto de oneroso en cada caso teniendo a la vista los pueblos contenidos en uno, dos, tres o cuatro repartimientos simultáneamente o en muy pocos años. Repartimientos, sobrecostos y quiebras.

En los años de referencia (1690-1696) se han recogido obras en 66 puentes, uno en La Mancha, 5 en Andalucía (uno de ellos en Gibraltar) y 3 en Extremadura, los 57 restantes entre la meseta norte y la cordillera cantábrica. Aquí he prestado atención a los puentes de Benavente, Alba de Tormes (solo para los costos administrativos), Covarrubias, Frómista, Lerma, Trespaderne y León. Es lógico encontrar pueblos incluidos en tres repartimientos casi simultáneos. Más aún, hay pueblos que están pagando por 6 puentes en el espacio de 5 años porque figuran en los repartimientos para los puentes de Palenzuela, Benavente, Frómista, Lerma, Quintana del Puente y León ${ }^{38}$. ¿Qué suponía esto? En Palencia - por el puente de Palenzuela- se asignan 28 maravedíes, pero se trata de un segundo repartimiento para cubrir «quiebras» del inicial que había supuesto un costo de algo más de 7 reales; para el puente de León se cobrarán 243 maravedíes/vecino; para el de Castro Gonzalo: 174 maravedíes /vecino; para los de Lerma: 311 maravedíes/ vecino. Resumen: en 4 pueblos hay que pagar 1.010 maravedíes, casi 29 reales y medio por vecino ${ }^{39}$. De acuerdo: gravamen oneroso, que no figura en las grandes cuentas de millones, alcabalas, servicios, etc.

Dicho esto, cabe subrayar que esta pugna lograba rectificaciones importantes en los costos de las obras, lo que permite matizar la tesis de Vela Santamaría, porque el Consejo sabía que reconstruir un puente era un gravamen «oneroso»,

38. AHN, RGS, para Palenzuela: leg. 7.537, 18 de abril, 1690. Para Castro GonzaloBenavente: leg. 7.544, 26 de mayo de 1691. Para Frómista: leg. 7.559, 22 de diciembre de 1692. Para Lerma: leg. 7.556, 4 de julio de 1693. Para Quintana (Quintanilla, en ocasiones) del Puente: leg. 7.574, 6 de mayo, 1694 y, finalmente, para León: leg. 7.586, 23 de junio de 1696.

39. Las Grañeras, Bercianos «del camino francés», Vallecillo, Gordaliza del Pino. Remito a cuadro 1 y 2 . 
pero intentaba reducir costos aunque el proceso se prolongara extraordinariamente. Las resistencias locales sumaban sus fuerzas a la lentitud de la administración y a la dificultad de las comunicaciones.

Los gobiernos locales -concejo, justicia y regimiento- sabían aprovechar el interés general del comercio para defender el interés particular. Escenificaban a la perfección el mal estado de puentes y calzadas, los riesgos, los peligros de toda clase para recordar que carecían de capacidad para las obras, bien por la escasez de población, bien por la carencia de propios o por la conjunción de ambos motivos, como alega expresamente Gibraltar.

\section{CONSTRUIR O REPARAR}

Apenas existen referencias a la construcción de puentes. Dos se han recogido, ambas en Andalucía: Gibraltar y Ronda, respectivamente. En 1695 se conceden arbitrios a Gibraltar para fabricar un puente de canto sobre el Cachón de Mayorga para sustituir otro de madera arruinado por las lluvias del año anterior, que habían incomunicado a la ciudad con los cortijos y haciendas de sus vecinos, así como cortado las comunicaciones con Jerez, Cádiz, Sevilla y otros puntos, sin contar la pérdida de vidas humanas ocasionada por la catástrofe ${ }^{40}$. La motivación de Ronda es distinta. Se necesita un puente que comunique la ciudad, en un proceso de despoblamiento, pues ya hay 200 casa abandonadas, con el mercadillo a donde se va trasladando la vida de la ciudad. La petición es de marzo de 1692 y en julio de 1693 el Consejo ordena ya el pregón de las obras ${ }^{41}$.

Por tanto estamos hablando de reparación de puentes. El proceso se inicia a petición de los lugares afectados que elevan memoriales al Consejo de Castilla cuyo contenido es prácticamente idéntico de unos a otros: el puente en cuestión es vital para las comunicaciones, pero se halla en tan mal estado que es un peligro real para viajeros y comerciantes. El lugar, en cambio, carece de propios para abordar las obras. El Consejo responde ordenando al corregidor más próximo que se informe personalmente y reúna todos los datos técnicos pertinentes acudiendo a maestros de cantería reconocidos. Estos elaboran un informe técnico y un estudio del costo de las obras que el corregidor eleva al Consejo para su estudio. Si el Consejo lo aprueba se pone en marcha un proceso de información pública y de apertura de pliegos de condiciones y precios - «traerlo al pregón»- que puede prolongarse durante años porque el Consejo está siempre a la espera de

40. AHN, RGS, leg. 7.583, 14 de noviembre de 1695 .

41. AHN, RGS, leg. 7.550, 22 de marzo de 1692 y leg. 7.566, 11 de julio de 1693. 
nuevas ofertas a la baja para adjudicar las obras. Agotados los plazos, se ordena un recuento de vecinos en los pueblos de 20 leguas a la redonda para prorratear el costo. Aprobado el remate de la obra, el Consejo ordena hacer el repartimiento después de haber estudiado las diversas alegaciones y protestas de los afectados.

Falta un último paso, la orden de ejecutar el repartimiento en el que se señalan depositarios para los ingresos y diversas garantías legales. Solo entonces pueden comenzar las obras ${ }^{42}$. Lo que sigue es una escenificación de este proceso mediante unos breves apuntes sobre diversos puentes.

\subsection{Benavente, 1691. El puente de nunca acabar}

Siguiendo un criterio cronológico, estudiamos en primer lugar el puente de Castro Gonzalo sobre el Esla, en Benavente. El voluminoso expediente de concesión de la licencia de obras data de mayo de $1691^{43}$ y recoge todo un historial de obras previas, de trámites eternos, como refiere Vela Santamaría ${ }^{44}$, que parecen no tener término. En 1680 se estaban haciendo diligencias por los peligros que se advertían dado el mal estado del puente de tal manera que el 2 de marzo de 1683 se había derrumbado parte del puente. Para entonces, y después de un meticuloso proceso con «vista de ojos»-inspección personal por el corregidor y técnicos in situ-, informes y estudios, se fijó el costo de la reparación de los arcos caídos y los que amenazaban ruina en 208.500 reales. Pero la obligación de pregonar las obras en Zamora, León, Toro y Tordesillas y el estudio de las ofertas retrasarían tanto la obra que los daños llegarían a ser mayores. Por ello, como solución de urgencia y con el fin de evitar retrasos, Benavente proponía fabricar un puente de madera sobre los pilares en pie, adelantando los 30.000 reales de costo, financiados con arbitrios sobre el vino. El 6 de octubre de 1683 el Consejo ordena pregonar la obra en los 208.500 reales, ignorando totalmente tal propuesta. Para 1684 la obra está en 192.000 reales. Benavente solicita se acepte y que se haga el remate en esa cifra, sobre la que nadie ha hecho ninguna otra oferta, pues ya son 8 años los que se está pregonando la obra.

Nuevos pregones rebajan la cantidad hasta los 180.000 reales que el Consejo acepta en 16 de julio de 1687. Acepta, asimismo, las fianzas que da el maestro de

42. Aramburu-Zabala, M. A.: La arquitectura..., op. cit., esquematiza claramente el proceso, p. 28 y 29.

43. AHN. RGS, leg. 7.544, 26 de mayo de 1691. El expediente comprende 51 «foxas». Aramburu-Zabala, M. A.: La arquitectura..., op. cit., hace un recorrido por los puentes castellano-leoneses, aporta buena información hasta 1660, más o menos, y luego salta a finales del s. XviII.

44. Cfr. supra, nota 21. 
obras por valor de 222.000 reales. Debido a la proximidad con Portugal se pide hacer el repartimiento en 30 leguas alegando, además, «el alivio de los vasallos».

Finalmente, en 9 de marzo de 1691, el Consejo mantiene la cifra de 180.000 reales y el reparto en 20 leguas, comprendiendo 35.172 vecinos, por lo que toca a cada uno 174 maravedíes (5 reales. y 4 maravedíes) quedando un déficit de 72 maravedíes. El 26 de mayo, un definitivo auto del Consejo da la licencia de obras; han transcurrido 10 años para que los 208.000 reales de partida se reduzcan a 180.000 . La rebaja de 28.000 reales no llegaba a un real por vecino, pero era una rebaja.

\subsection{Alba de Tormes $1691^{45}$}

El remate tiene fecha de diciembre de 1690, pero los últimos documentos emanados del Consejo precisando la forma de cobrar los costos administrativos están fechados en 24 de diciembre de 1691. Es un expediente muy completo porque incluye datos valiosos sobre técnicas y materiales de construcción para rehacer totalmente los nueve arcos de cantería y sus cepas que se han llevado las riadas, la reparación de los tajamares, hacer los «socalios» y empotrados. Incluye el listado de las poblaciones de 20 leguas en contorno. Partiendo de los 38.000 ducados fijados en 1686, 418.000 reales, se remata en 28.000 ducados, 308.000 reales en 17 de diciembre de 1690. El costo final es de 11.459.070 maravedíes (10.472.000 las obras más 987.000 costos administrativos), repartidos entre 31.468 vecinos a 364 maravedíes/vecino. El «alivio de los súbditos», en este caso, es de 110.000 reales.

\subsection{Covarrubias, 1692}

El expediente ${ }^{46}$ se abre con la información de que ya se habían pregonado muchas veces los reparos y obras del puente sobre el Arlanza y que, finalmente, se habían rematado en Sebastián Andrés de la Sierra en 32.360 ducados. Juan de la Riba hace una rebaja de la cuarta parte dejándolo en 24.260 (hay un error en el

45. AHN, RGS, leg. 7.537, 10 marzo 1690; leg. 7.544, 27 de junio de 1691; leg. 7.547, 24 de diciembre de 1691. Para las técnicas de construcción: García TAPIA, N.: Técnica y Poder en Castilla durante los siglos XVI y XVII. Salamanca, 1989, p. 40.

46. AHN, RGS, La documentación sobre este puente está contenida en 4 expedientes: leg. 7.545, 4 de julio de 1691 aporta brevemente los datos finales; leg. 7.548, 14 de enero de 1692 con la orden de hacer el repartimiento; y leg. 7.553, 14 de junio de 1692 contiene el repartimiento pormenorizado, es el documento que utilizamos principalmente por su carácter de síntesis de los demás y leg. 7.559, 19 de diciembre de 1692 con datos escuetos desde luego, posteriores al repartimiento, por lo que no resulta fácil de utilizar.

Ediciones Universidad de Salamanca / 뾰 Stud. his., H. ${ }^{a}$ mod., 39, n. 2 (2017), pp. 257-291 
documento, pues la cifra real es la de 24.270) con la cuarta parte de prometido ${ }^{47}$ y a condición de que se pregonase nuevamente la obra. El Consejo fue ordenando nuevos pregones en Valladolid, Sto. Domingo de la Calzada, Burgos, Santander, San Vicente de la Barquera, Laredo, Castro Urdiales y Pancorbo y, posteriormente, también en la Corte. El 20 de diciembre de 1691, el Consejo, oído el fiscal, da provisión al corregidor de Burgos para que se haga el repartimiento y lo remita al Consejo antes de ejecutarlo. El repartimiento lleva fecha de 14 de febrero de 1692. En resumen: casi 90.000 reales menos, lo que va de los 355.060 reales iniciales a los 266.970 del remate final. Desde el punto de vista del «alivio de los vasallos» una precisión más. Existe una información adicional de 19 de diciembre de 1692. En esa fecha el Consejo acepta una baja de 6.000 ducados hecha por un vecino de Cudeyo, dejando el costo final en 198.000 reales, es decir otra rebaja de 68.970 reales ${ }^{48}$.

\subsection{Villarta, 1692}

Un proceso complejo según se deduce del expediente ${ }^{49}$. Los trabajos administrativos para el puente sobre el Cigüela y el Záncara se inician en la década de los 70, puesto que se habla de una primera averiguación de vecindad en 1679 para hacer un repartimiento. La segunda averiguación se hace en 1689 seguida de un repartimiento parcial, para completar las «quiebras» de los anteriores. El último repartimiento se hace sobre un total de 65.810 vecinos, entre los que se reparten 6.186 .140 maravedíes, equivalentes a 181.945 reales, correspondiendo a cada vecino 94 maravedíes, 2 reales y 26 maravedíes.

\subsection{Frómista, 1692}

En 1692 se concede la licencia para las obras del puente sobre el río Uzieza y la calzada y puente Regañadas y Pedro Vedija en Frómista ${ }^{50}$. El proceso administrativo, en cambio, se ha iniciado en 3 de diciembre de 1671, con una petición de Frómista ante el Consejo. En virtud de provisión real, se hace una inspección y en 4 de junio de 1672 se redacta el pliego de condiciones y costos evaluados en 171.500 reales. El 12 de agosto de 1682, diez años después, se hace públicamente

47. Diccionario de Autoridades, «Prometido: Se llama en las posturas o pujas, aquella talla que se pone de quota, y ha de pagar el que hace mejora». Madrid, 1979, T. O-Z.

48. AHN, RGS, leg. 7.559, 19 de diciembre de 1692.

49. AHN, RGS, leg. 7.554, 12 de julio de 1692.

50. AHN, RGS, leg. 7.559, 26 de noviembre de 1692.

Ediciones Universidad de Salamanca / 뾰 Stud. his., H. ${ }^{a}$ mod., 39, n. 2 (2017), pp. 257-291 
el remate en Palencia en 82.500 reales. El 22 de septiembre de 1692 se hace el repartimiento por 21.749 vecinos, correspondiéndole a Frómista el 10\%, o sea 8.250 reales. Precisemos: 74.250 reales más los 8.250 de Frómista y se cuentan, pero no se reparten, los 6.875 reales de prometido. En 22 años, grosso modo, este puente y calzada ha salido un $44 \%$ más barato, 61.500 reales menos.

\subsection{Lerma, 1693}

En 1693 se da la licencia para las obras de dos puentes en Lerma, el de Valdenebreda y otro sobre el río Arlanza ${ }^{51}$. Las primeras cifras elevan el costo a 32.300 ducados, es decir, 355.300 reales. Tras sucesivos pregones en 7 de noviembre de 1691, Moncalián, maestro de cantería, ofrece hacer la obra por 29.300 ducados, o sea 322.300 reales. El Consejo ordena hacer el repartimiento ${ }^{52}$. Pero en un momento indeterminado alguien ha hecho una oferta por 21.965 ducados, o 241.615 reales. En 13 de abril de 1693, el Consejo obliga a Moncalián a aceptar la obra de los dos puentes en los 21.965 ducados o 241.615 reales. En 5 años se da una rebaja de 113.686 reales, casi un 32\%. Ahora bien, en 26 de mayo de 1693 el Consejo ordena hacer un repartimiento de 9.379 .444 maravedíes entre 30.130 vecinos, con un superávit de 9.014 maravedíes y tocan a 311 maravedíes/vecino (8 reales y 30 maravedíes), cantidad que equivale a 275.866 reales, muy por encima de lo impuesto a Moncalián. Aunque no haya constancia documental parece que constructor y Consejo hubieron de llegar a algún acuerdo.

\subsection{Trespaderne ${ }^{53}$}

En 22 de mayo de 1676, el Consejo provee un auto para que el corregidor de las merindades de Castilla la Vieja visite Trespaderne y revise el puente sobre el Ebro con maestros expertos para realizar un proyecto de obras y condiciones y remitirlo al Consejo. A la vista de esos informes en 10 de julio de 1677 el Consejo ordena pregonar las obras y admitir posturas y bajas. El 29 de marzo de 1680 un maestro de cantería hace una rebaja de 2.500 ducados sobre la cantidad que -refiere- estaba puesta anteriormente en 24.000 ducados -264.000 reales-, dejándola en 21.500 ducados. Entre 1680 y 1690 se repiten las inspecciones, los pregones, el baile de cifras, los informes al Consejo. A finales de 1692 el maestro Felipe de la Lastra ofrece hacer las obras por 16.135 ducados, o sea, 197.900 reales,

51. AHN, RGS, leg. 7.556, 4 de julio de 1693.

52. AHN, RGS, leg. 7.559, 19 de diciembre de 1692.

53. AHN, RGS, leg. 7.571, 12 de diciembre de 1693.

Ediciones Universidad de Salamanca / 뾰 Stud. his., H. ${ }^{a}$ mod., 39, n. 2 (2017), pp. 257-291 
pero en marzo de 1693, y ya fuera de plazo y sin garantías, alguien ofrece bajar a 13.493 ducados, o sea, 148.423 reales. El Consejo hará que Felipe de la Lastra acepte la obra en esos 13.493 ducados, o 148.423 reales. Resumen: si en 1677 las obras estaban tasadas en 264.000 reales, 15 años después se han reducido a 148.423 reales con un ahorro de 115.577 . Evidentemente, no era mera literatura la fórmula que emplea el Consejo en todos los expedientes revisados: alivio de los vasallos.

\subsection{León $^{54}$}

El expediente sobre el puente de León tiene un largo recorrido. En 1670 ya se habían gastado 51.500 reales para encauzar el río Bernesga y obligarle a pasar nuevamente bajo el puente de S. Marcos. El empleo de madera y piedra no fue suficiente y en 1692 se está en la misma situación. Ahora los maestros de cantería calculan el costo de las nuevas y definitivas obras en 20.000 ducados $^{55}$. Las peticiones de pregonar ya las obras se suceden y matizan. Se confirma la cifra de 220.000 reales, rebajando levemente la propuesta inicial de Antonio Solar y Felipe de la Lastra, de 225.000 reales. Así que el 30 octubre de 1692 el Consejo ordena nuevos pregones, logrando bajar a 210.000 reales. El 16 de noviembre de 1694 se acepta la propuesta y las fianzas, estas ocupan una parte notable del documento.

En 24 de febrero de 1696 el corregidor ordena que los contadores hagan el repartimiento de los 210.000 reales de la obra, de los 13.000 del desmonte del terreno y de los 428.000 maravedíes de los costos administrativos. Se ha de cobrar un total de 235.588 reales y 8 maravedíes que se reparten entre 32.869 vecinos, asignándole a cada uno 243 maravedíes y sobran 2.036 maravedíes para quiebras. Termina repartiéndose a 244 maravedíes (7 reales y 6 maravedíes), pues los 2.036 maravedíes sobrantes no se pueden prorratear por ser cantidades mínimas. Ahora sobran 10.036 maravedíes (295 reales y 6 maravedíes) para quiebras. La licencia, finalmente, es del mes de junio de 1696. En sí el proceso es corto y se resume en una rebaja de 15.000 reales.

\section{Costos administrativos}

Los costos de las obras se escalonan a lo largo de tres fases: búsqueda de información, toma de decisiones y ejecución. Cada fase requiere un tipo de personal

54. AHN, RGS, leg. 7.586, 23 de de junio 1696. Es útil la consulta de los planos anexos de Fernández Ordóñez, J. A., Abad Balboa, T., Chías Navarro, P.: Catálogo de puentes anteriores a 1936. LEÓN, 1988, especialmente «Evolución de la Caminería Antigua (Siglos ViII Al XViII).

55. AHN, RGS, leg. 7.541, 8 de noviembre de 1690. 
que debe ser retribuido. Es en estos momentos cuando el Consejo puede hacer sentir más directamente su política de «alivio de los vasallos» mediante actuaciones concretas, pero la «ejecución» ya no está controlada por el Consejo. Antes del comienzo de la obra, en el proceso de licitación, insiste una y otra vez en pregonar las obras para lograr rebajas sustanciales, conseguidas en todos los casos expuestos. Pregones repetidos en las cuatro ciudades o villas más próximas, incluso en los puertos del Cantábrico y los valles de la Montaña de donde eran originarios los canteros que debían dar fianzas «abonadas» ${ }^{56}$. Tal práctica chocaba con las prisas de los pueblos deseosos de comenzar las obras rápidamente. En segundo lugar, venía la negociación y presión a los maestros canteros para que rebajasen los conceptos, probablemente excesivos, por gastos de gestión y administración que pretendían repercutir en los vecinos.

La reparación de un puente movilizaba un numeroso equipo de personas: corregidor, alguaciles y escribanos; maestros de cantería, pregoneros, depositario general, veedores y contadores que controlaban al depositario general, juez protector de puentes, escribano de puentes distinto, en su caso, de los que acompañaban al corregidor; verederos $s^{57}$ y personal que repartiese los cupos. Todos ellos tenían una retribución y era preciso, además, formalizar expedientes con toda la documentación del caso.

Con los corregidores han de incluirse los gastos de alguaciles y pregoneros. En efecto, el corregidor cumplimenta las instrucciones recibidas y eleva un informe al Consejo que lo estudia y le devuelve con nuevas instrucciones, en virtud de las cuales el corregidor ordena pregonar las obras y recibir propuestas elevándolo todo nuevamente al Consejo. En este momento algunos pueblos acuden al Consejo instando a que se inicien ya las obras, pero el Consejo responde ordenando nuevas tandas de pregones por 30 días para lograr rebajas. Las visitas a las obras propuestas $\mathrm{y}$ otras, se hacen con la presencia de alguaciles y escribanos.

Los gastos están tasados por día y categoría profesional. Al corregidor se le asignan 1.200 maravedíes/día, 500 al alguacil y 400 al escribano, que cobra también

56. Todo ello exhaustivamente documentado ya en la tesis de Aramburu-Zabala. Ver nota 6. Las fianzas que aportan los maestros del puente de León cubren más de la mitad del expediente administrativo.

57. Sobre la actuación de los «verederos» da una idea la siguiente anotación referida a Medina del Campo. A petición de los procuradores generales de Medina, el Consejo emite un auto para que los verederos que se hayan de enviar a Medina vayan con una comisión muy ajustada en que conste taxativamente los lugares que han de visitar, las distancias a estos lugares y las cantidades asignadas a estas visitas. Y, finalmente y sobre todo, estos extremos habrán de ser elaborados por los regidores de Medina, buenos conocedores del territorio. AHN, RGS, leg. 7.568, 14 de diciembre de 1696. 
por otros conceptos. Contadores y depositarios tienen asignadas cantidades fijas, proporcionales a los costos de las obras. Los verederos son el último escalón del sistema, pero son los que hacen el trabajo de base, junto con ejecutores y repartidores, todos ellos dirigidos por el escribano.

El apartado de la «documentación» es complejo: autos, provisiones, requisitorias, traslados, peticiones, repartimientos, ejecutorias. Hay que incluir aquí también el concepto de «imprimir cupos», que a veces se menciona expresamente como distinto de verederos y repartidores que actuarían como meros «correos» físicos.

El control final de todo el proceso requiere una nueva figura: el defensor del puente o de los puentes. En general, no se le asignan actuaciones ni competencias concretas, lo cual resulta extraño en obras tan largas, complicadas y conflictivas, pero es una figura que no podía faltar en la estructura administrativa de la época, donde cada sector acudía en primer lugar a «su» juez privativo. En el expediente para el puente de San Marcos de León se le asignan funciones concretas, asimilables a las del secretario de una organización, pues se le paga por «formar los libros» y custodiarlos.

La cuestión es en qué grado tales gastos eran imputables a la obra, en cuyo caso pagarían los pueblos, o a la gestión de la obra, concepto que no venía contemplado en la facultad concedida por el Consejo que exigía a los pueblos justificar todos sus gastos. La cuestión, pues, se traslada a cómo elaboraban sus presupuestos los maestros en quienes se remataba la obra. Así pues, obra y gestión. El primer presupuesto lo hacen maestros de cantería o arquitectos que luego no podrán ejecutar las obras, lo que les da una cierta libertad a la hora de evaluar los gastos. Enfrente está el Consejo, cuyo interés primordial es el control de las justicias y haciendas locales, y no los aspectos técnicos de las obras. Por otra parte, los gastos que aquí se contemplan no son por conceptos de la Hacienda Real, sino de la municipal, obligatorios para las justicias y regimientos locales ${ }^{58}$ y que deberían pagarse con los «propios» de cada pueblo. Castillo de Bobadilla recalca esta obligatoriedad, sirva como ejemplo esta anotación sobre lo que por provisión real deben pagar los pueblos de sus propios: «para puentes muy frequentadas y passageras de harrieros para el comercio destos Reynos [...] como se hizo para esta villa de Madrid, que es la mejor dellas» ${ }^{59}$.

58. La Legislación es clara al respecto. Los pueblos deben financiar con sus propios obras públicas: caminos, puentes, fuentes, edificios públicos. Novísima Recopilación de las Leyes de España. T. III. Libro VII, De los pueblos y de su gobierno civil, económico y político». Título 35: De los caminos y puentes., etc., Madrid, 1992, fol. 671 y ss.

59. Castillo de Bobadilla, J.: Política para corregidores y señores de vasallos... y para juezes eclesiásticos y seglares. Madrid, 1992, T. II, lib. V, cap. IV, fol. 576. 
Más adelante explica que los propios y comunes de los pueblos son como la «dote» que el Príncipe les concede y que debe proteger y administrar ${ }^{60}$. Para ello se vale de la repetición de los pregones.

He aquí, pormenorizados, los gastos de algunos de estos puentes.

\subsection{Benavente}

Los maestros piden se les entregue «líquida y enteramente» los 180.000 reales exclusivamente para la obra y solicitan se añadan y se incluyan en el repartimiento otros 14.000 reales, alegando que los han ido adelantando de su propio dinero desde 1682, porque «semejantes gastos los an sattisfecho siempre los contribuyentes de la cantidad principal». Esta es la relación de conceptos de tales gastos:

despachos y ejecuciones que se an sacado del Consejo [...] para diferentes dilixençias, repetidos pregones en distinttas partes y para rematte y aprovazión del en el Consejo, gasto del ajustte de vezindades que fue muy considerable, y en el que se espera casi de la misma cantidad, en la distribución de los cupos de pago, derechos de juezes y del escribano que tan vien son considerables por darse copia y traslado de cada despacho y auttos que se buelven a remitir al Consexo, ocupazión y travajo de los conttadores, y el uno y medio por çientto que el depositario deve haver.

El Consejo pide al corregidor de Benavente un informe exhaustivo con el fin de ver qué cantidades se podrán incluir en el repartimiento, teniendo en cuenta «lo que se a echo bueno a los maestros de puentes en otros repartimientos... Para que se provea lo que convenga» ${ }^{61}$.

\subsection{Alba de Tormes}

Los costos administrativos según los concesionarios de la obra alcanzan 987.000 maravedíes (29.029 reales) que el fiscal del Consejo, Matheo López de Dicastillo rechaza por excesivos, pidiendo, y obteniendo, que se modere y limite la cantidad. El auto de 27 de noviembre de 1.691 autoriza el reparto de los 28.000 ducados de la obra, haciendo constar expresamente que los 987.000 maravedíes quedan reducidos a la tercera parte, aplicándose esta rebaja lineal a cada uno de

60. Ibidem, «el Señorío de los bienes de los pueblos es dellos, y fundan su intención de Derecho quanto a la propiedad y possessión dellos. [y volviendo al concepto de dote] y assi es propio de su attributo y naturaleza Real governor, proveer y ver como sustenta, gasta y comunica a los miembros, y a su pupila y esposa [la república, los pueblos\} la sustancia y facultad della...», t. II, lib. V, cap. IV, fols. 573-574.

61. AHN, RGS, leg. 7.544, 26 de mayo de 1691.

Ediciones Universidad de Salamanca / 
los conceptos, quedando en 329.000 maravedíes ( 9.676 reales y 16 maravedíes) y se han excluido del reparto 658.000 maravedíes (19.352 reales) ${ }^{62}$.

\subsection{Covarrubias}

Este puente le permite al Consejo consolidar criterios fijos. En efecto, para los puentes de Sta. María del Campo y Cerracín se habían fijado los costos de averiguación de vecindad y entrega de los cupos en 10.000 reales. En Covarrubias el Consejo los rebaja a 8.000 reales (272.000 maravedíes), porque, recuerda, así se ha procedido para el puente de Belorado. Esta cantidad va a ser la norma en puentes sucesivos. El mismo criterio de continuidad se aplica a los gastos del escribano mayor de puentes. La misma cantidad para el contador de puentes que percibe por tener el correspondiente «real título». Al depositario general de Burgos, en cuyo poder entran los maravedíes del repartimiento, se le señalan 136000 maravedíes, por «tener cédula de Su magestad» ${ }^{63}$.

\subsection{Villarta}

Para julio de 1692 se han hecho ya 4 «vistas de ojos» a cargo de los corregidores de Toledo y Ciudad Real, con un costo de 8.000 reales, y se espera una quinta y última finalizada la obra, que tiene asignados 2.150 reales. Se han hecho cinco requisitorias, con un costo de 11.097 reales. Las obras se han pregonado en Ciudad Real, Ávila, la Corte, Segovia, las Cuatro villas de la mar, Almagro y Daimiel, Consuegra, Alcázar de S. Juan y Villarta. En resumen, el maestro Simón Martínez de la Vega está pidiendo por estos y otros conceptos 54.319 reales adicionales que ha adelantado. El Consejo sigue su práctica habitual: estudiar bien el expediente para reducir el importe o, simplemente, para rechazarlo, pero en este caso no conocemos la cifra final ${ }^{64}$.

\subsection{Frómista}

Los conceptos son similares ${ }^{65}$. Se individualiza la labor de los 10 verederos, que ha comprendido 247 días de trabajo, con un mínimo de 10 días y un máximo de 29. Por este y los demás conceptos se piden 8.908 rs y el Consejo los reduce

62. AHN, RGS, leg. 7.547, 24 de diciembre de 1691.

63. AHN, RGS, leg. 7.553, 14 de junio de 1692.

64. AHN, RGS, leg. 7.554, 12 de julio de 1692.

65. AHN, RGS, leg. 7.559, 26 de noviembre de 1692.

Ediciones Universidad de Salamanca / 뾰 Stud. his., H. ${ }^{a}$ mod., 39, n. 2 (2017), pp. 257-291 
JESÚS BRAVO LOZANO

ALIVIAR A LOS VECINOS: EL CONSEJO DE CASTILLA Y LAS OBRAS PÚBLICAS

EN EL REINADO DE CARLOS II. PUENTES Y VECINOS

a 4.000 , un $44,9 \%$, con orden de prorratear la rebaja en todas las ciudades, villas y lugares.

\subsection{Lerma}

Se aplica directamente el modelo de Covarrubias. Son fijos los 8.000 reales (272.000 maravedíes) de «aberiguazión de vezindades y entrega de los mandamientos que las personas que nombraren an de llevar a las ciudades, villas y lugares», alcanzando la cifra final 442.000 maravedíes (13.000 reales) ${ }^{66}$.

\subsection{Trespaderne ${ }^{67}$}

Los costos administrativos se desglosan en 56 puntos que incluyen los gastos de averiguación de vecindades en los partidos de Burgos, Aguilar de Campoo, Villadiego, Campoo, Santillana y los nueve valles, Laredo, los valles de la Montaña, Rioja Alta y Baja, gastos de papel, de papel sellado: «300 fojas de escritos... 482 hojas de traslados... 10 cuadernos y más de 1.500 hojas», en diligencias de las audiencias de todo el proceso... y, finalmente 2 contadores que hacen el repartimiento. Todo asciende a 520.788 maravedíes. (15.317 reales y 10 maravedíes). Ahora bien, el Consejo, siguiendo sus criterios de «alivio de los vasallos», recorta notablemente algunos capítulos. Los días que los escribanos justifican para hacer las vecindades suman 241, pero el Consejo los «modera» a 149, es decir un 38,17\% menos; en términos monetarios: de 96.400 a 59.600 maravedíes (de 2.835 reales y 10 maravedíes a 1.752 reales y 22 maravedíes). En conjunto, esos 520.788 maravedíes el Consejo los rebaja en una tercera parte.

El proceso se inicia en 1.675 con una anotación de 3.600 maravedíes al corregidor de Burgos por una primera «vista de ojos» que dura 3 días. Ante el deterioro del puente, el Consejo ordena en mayo de 1.676 nueva «vista de ojos» que dura 4 días. Las obras comienzan a pregonarse en julio de 1677 en Villarcayo, Burgos, Sto. Domingo de la Calzada y Trespaderne, en 24 de abril de 1679 se ordena repetir los pregones en las localidades citadas y se añaden Santander y Laredo; en 1.680 añade Miranda de Ebro, ese mismo año en noviembre se manda pregonar nuevamente la obra, dándose 130 pregones. Y aún hay nuevas asignaciones a lo largo de 1684, 1685, 1689 y 1692, con pregones también en el lugar de «OZ» (Hoz) de la

66. AHN, RGS, leg. 7.556, 4 de julio de 1693. En Lerma no hay cantidad asignada al contador de puentes reales, por lo cual los costos son de 442.000 maravedíes, frente a los 476.000 de Covarrubias.

67. AHN, RGS, leg. 7.571, 12 de febrero de 1693. 
merindad de Trasmiera. El resultado se traduce en tres «trazas» de tres maestros de cantería y 647 reales más.

\subsection{León}

La información sobre el puente de León es la más completa de las que se han consultado. Comprende los capítulos de reconocimiento de la obra, informes, pregones, aprobación del remate y del repartimiento, los 528 días de trabajo de 22 verederos para hacer los vecindarios, más los 180 días que emplean 6 verederos para repartir 636 cupos en las cabezas de partido, mas los pagos al corregidor, escribanos, defensor de puentes, y dos contadores. Todos estos conceptos suman 762.200 maravedíes (22.417 reales y 22 maravedíes). Al Consejo le parecían excesivos y ordenó revisarlos a la baja, «moderación de gastos», lo que se hace en 23 de febrero de 1696. Los recortes suman 334.000 maravedíes (9.823 reales, un $43,8 \%$ ). En consecuencia el costo final por estos conceptos queda en 428.000 (12.058 reales, 28 maravedíes).

Para cerrar este apartado y a modo de resumen se aporta la justificación que hace el Consejo de su proceder con motivo de las obras de Quintana del Puente. Se ha hecho un reparto de 189.200 reales entre 25.587 vecinos correspondiendo 254 maravedíes a cada vecino, lo que hace que sobren 66.298 maravedíes que se destinan a cubrir posibles quiebras, y de ninguna manera a gastos de gestión o administración: «salarios de veedor, depositarios, verederos escribano y gastos de requisitorias que se avían despachado, que todo ello ynportava más de 20.000 reales...» que el contador no quiso incluir en el repartimiento dejándolo al arbitrio del Consejo «Y porque por ser precisos y necesarios dichos gastos siempre se había considerado por nos [el Consejo] la mitad que había parecido ser competente». El Consejo enuncia, pues, el principio de que estos gastos se reducirán automáticamente a la mitad de lo pedido por los maestros, aunque no se aplique siempre en todo su rigor ${ }^{68}$.

\section{VECINOS}

El correlato de los puentes son los vecinos que se benefician en muy diversos grados - sin olvidarnos de aquellos que no encuentran utilidad inmediata alguna- y los pagan. Es, pues, el momento de prestar atención a los vecindarios.

68. AHN, RGS, leg. 7.574, 6 de mayo de 1694.

Ediciones Universidad de Salamanca / 뾰 Stud. his., H. ${ }^{a}$ mod., 39, n. 2 (2017), pp. 257-291 
A la hora de estudiar la demografía de finales del xvir estos vecindarios tienen valor como dato positivo, pero muy necesitado de matizaciones. La Corona precisaba conocer el número de habitantes y ordenaba realizar recuentos con frecuencia. El estudio clásico de Bustelo sobre el vecindario de Campo Florido de 1717 recuerda que entre 1712 y 1717 , en el contexto de la guerra se hacen seis «imposiciones de carácter extraordinario... Y fue para recaudar dicho gravamen para lo que se confeccionaron vecindarios en todo el país» ${ }^{69}$, de carácter fiscal. Esa finalidad ha exigido a los estudiosos afinar extraordinariamente la validez de tales vecindarios por los problemas que plantean de sobra conocidos: la conversión de vecino en habitantes ${ }^{70}$, las particularidades de la investigación a través de verederos, etc., ocultaciones por parte de los pueblos que se temían siempre algún impuesto nuevo.

De los vecindarios aquí manejados llama la atención dos aspectos: el trabajo de los verederos y la complejidad jurisdiccional del territorio. De ello depende en parte la fiabilidad o las dudas que tengamos ante estos documentos. Por ejemplo, ¿qué grado de precisión pueden tener las anotaciones sobre los valles de León colindantes con Galicia y Asturias, o los concejos asturianos? Si los verederos obtienen sus datos in situ de las autoridades locales es posible que los datos aportados por los titulares de señoríos eclesiásticos sean más exactos que los de realengo. Es bien claro esto en las anotaciones de la abadía de S. Andrés de Espinaredo, o de S. Pedro de Montes, porque a continuación se enumeran sus lugares con sus vecinos y la anotación: lugar de la abadía de S. Andrés de Espinaredo, o de S. Pedro de Montes ${ }^{71}$. Lo contrario sucede con anotaciones como: «tierra» $\mathrm{O}$ «alfoz». Por ejemplo: «Lugares del alfoz de Carrión; diez villas de la Baldavia; diezyocho lugares de la jurisdicción de Mansilla..., Saldaña y su jurisdicción con las 30 villas de la Baldavia y Buena Vista..., Benavente, su jurisdicción, comenderos y agregados..., los 42 lugares comprendidos en la jurisdicción de Alcañices», agrupados en tres anotaciones. En estos casos los verederos posiblemente se conformaban con las cifras aportadas por la cabeza de jurisdicción ${ }^{72}$. Hay poblaciones que han comprado la exención del pago de este impuesto, por tanto no aparecen en las

69. Bustelo García del Real, F.: «El vecindario general de España de 1712-1717 o Censo de Campo florido (I)», Revista Internacional de Sociología. XXXII:7-8, 1973, p. 86.

70. LanZa García, R.: «El vecindario de 1683: una fuente inédita para el estudio de la población de la Corona de Castilla», Revista de Historia Económica, XXIII:2, 2005, pp. 335-369, dedica todo el apartado número 2 a este tema «A vueltas con el viejo problema del coeficiente...», pp. 342-349.

71. AHN-RGS, leg. 7.586, listado del vecindario, para el repartimiento del Puente de S. Marcos, León, junio 1696.

72. Ibidem. 
relaciones elevadas al Consejo. Puede suceder lo contrario, que aparezcan pueblos no incluidos en las 20 leguas del reparto. Castilla necesita conocer sus recursos y empieza por lo más fácil aparentemente: recursos humanos. Pero las apariencias pueden resultar engañosas, a pesar del trabajo de verederos y escribanos y de la profesionalidad de los delegados superiores según la opinión de Lanza sobre estos últimos ${ }^{73}$. Veamos. Pinos y el concejo de Babia de Yuso (ambos en León) contabilizan en el repartimiento para los puentes de Domingo Flórez y Puente Nueva por 152 y 220 vecinos respectivamente, siendo así que no son más de 49 en Pinos y 138 en Babia de Yuso, «y muchos exentos» ${ }^{74}$. Se deja para el final 3 cuadros con datos comparativos de diversos vecindarios.

\subsection{Todos los vecinos}

Queda por resolver otro problema. En estos vecindarios ¿̇se recogen todos los vecinos o tan solamente los pecheros? En principio hay que aceptar que se recogen todos los vecinos, sin distinción. Es decir, tanto los pecheros como los hidalgos, no habría, por tanto, «exentos» y esto porque tales vecindarios no son «padrones» para repartir el servicio ordinario y extraordinario. Vela Santamaría recoge que además de los vecinos contribuyen las instituciones. En estos vecindarios de finales de siglo no se encuentra nada al respecto.

Desde el punto de vista jurídico queda claro que puentes, fuentes, fortalezas, castillos, etc., son responsabilidad de todos los habitantes, de la comunidad como tal que los financia, en primer lugar, con sus propios y está contemplado que si las obras afectan otros pueblos o intereses más generales, puedan ser financiados por repartimientos aprobados por el Rey ${ }^{75}$. Castillo de Bobadilla y, posteriormente, Bustillo de Santayana glosan esto textos legales con toda claridad y precisión. «Puede (el corregidor) compeler a los hidalgos, y a otros essentos seglares, que contribuyan con sus haziendas para hazer y reparar los muros, fortalezas,

73. LanZa García, R.: «El vecindario...», op. cit., pp. 337-342, con el estudio de los informes de varios superintendentes para elaborar padrones para los nuevos encabezamientos, «resulta razonable concluir que los ministros reales se emplearon a conciencia con el fin de disponer de datos ciertos y fidedignos...», p. 341.

74. AHN, RGS, leg. 7.580, 25 junio 1695; «y muchos exentos...» habría que interpretarlo como una argucia del concejo para reducir el cupo asignado, porque estos repartimientos no son de tipo fiscal, como los padrones para el servicio ordinario y extraordinario.

75. Novísima Recopilación..., op. cit., T.III., Libro VII, De los pueblos y de su gobierno civil, económico y politico. $\mathrm{T}^{\mathrm{o}} 34$ : De las obras públicas, y to 35 : De los caminos y puentes, fols. 672-681. 
fuentes, puentes, puertas, caminos, calles y calçadas» ${ }^{76}$. Santayana es más directo: «El contribuir al gasto de estas cosas (limpiar lagunas, muladares...) nunca se ha estimado carga personal; de otra suerte se diría que ni el hidalgo ni el clérigo debía contribuir para la fábrica de puentes o fuentes, por necesitar estas de acciones personales, de que están exentos» ${ }^{77}$.

En Tarancón, las justicias y el regimiento piden al Consejo que el repartimiento para las obras del puente de Villarta comprenda expresamente a eclesiásticos e hidalgos, lo que el Consejo autoriza automáticamente ${ }^{78}$. En Villanueva de los Infantes, se han contabilizado 1.039 vecinos, pero la villa solicita se haga el repartimiento tan solo sobre 607, porque los otros 422 son pobres de solemnidad. Deduzco, por tanto, que se incluye a todos los habitantes independientemente de su estatus jurídico político y que únicamente se excluye a los «pobres de solemnidad» ${ }^{79}$. En los pueblos al norte del sistema central no se alude para nada a esta distinción entre hidalgos y pecheros, mientras que solo al sur del sistema, donde se detecta menor actividad reparadora, se debe mencionar expresamente la obligatoriedad general de contribuir.

\subsection{Vecinos de León}

Estos vecindarios confirman a grandes rasgos lo que ya sabemos sobre la distribución de la población al norte y al sur del sistema central. El repartimiento de León comprende poblaciones de las actuales provincias de León, Palencia, Zamora, Valladolid y Asturias. La mayoría pertenece a la actual provincia de León, y en ellos vamos a fijarnos. El repartimiento de León arroja gran cantidad de entidades de población por debajo de los 10 vecinos y muy pocas por encima de los $500^{80}$. Esto mismo se repite en los recuentos hechos para los demás puentes de la meseta norte.

Para el puente de León los verederos recorren 625 poblaciones (suponiendo que no quieren, o no pueden, o no se les permite visitar todos los pueblos que

76. Castillo de Bobadilla, J.: op. cit., T. II, lib. III, cap. VI, ver nota 54.

77. Santayana Bustillo, L.: Gobierno Político de los pueblos de España y el corregidor, alcalde y juez en ellos. Estudio preliminar: Francisco Tomás y Valiente. Madrid. 1979. p. 111.

78. AHN, RGS, leg. 7.538, 9 de junio de 1690.

79. AHN, RGS, leg. 7.557, 7 de octubre de 1692.

80. Para la población de León en estos años, agrupada en 1.358 unidades de población, o «pequeñas comunidades de aldea en el $74 \%$ de los casos cuentan con menos de 50 vecinos (200 habitantes)» a la altura de 1787, Rubio Pérez, L. M.: «Párrocos, Parroquias y Concejos: el modelo parroquial leonés en el marco de las comunidades rurales y concejiles durante la Edad Moderna», Obradoiro de Historia Moderna, 22, 2013, pp. 129-163.

Ediciones Universidad de Salamanca / 요 Stud. his., H. ${ }^{a}$ mod., 39, n. 2 (2017), pp. 257-291 
comprenden algunas jurisdicciones), y recuentan 32.869 vecinos, un promedio de casi 53 por núcleo. Desmenuzando brevemente. Solo León supera la cifra de 1.000 vecinos -se le atribuyen 1.500 , lo que parece ser una estimación global ${ }^{81}$, , por debajo de León hay otras 15 entidades con más de 100 vecinos, de más a menos: Valencia de Don Juan, Mayorga sola, sin su jurisdicción; la ciudad de Astorga, Ponferrada -sin su jurisdicción-, Sahagún, Becerril de Campos, Ampudia, Valderas, La Mota, Frechilla, Molina Seca, Laguna de Alba del Páramo, Páramo de Ribas de Sil y Villabrágima, (suman: $3.925,5)^{82}$.

Un segundo bloque está formado por entidades jurisdiccionales, sean tierra, Concejos, u otras denominaciones, un territorio amplio entorno a León, tanto al este: Cea, Saldaña y su jurisdicción (806 vecinos), etc., como hacia el oeste y el suroeste: Benavente (con su jurisdicción comenderos y agregados: 2.737), las tierras de Alcañices, los pueblos de la jurisdicción de Sanabria o algunos de la jurisdicción de Zamora; luego hacia el noroeste y el norte: Bembibre y su jurisdicción, 717 vecinos; los concejos del norte y los asturianos limítrofes ${ }^{83}$.

Un último apartado engloba las poblaciones entre 0 y 99 vecinos, aunque forzosamente también aquí faltarán los núcleos comprendidos en lo que el texto designa como «lugares de la jurisdicción de...». Suman 353, de los cuales hay: 94 poblaciones con 10 vecinos o menos (un 15,04\%) incluidas algunas con 2 vecinos, como S. Martín de la Fuente y otros dos lugares; otros de 3 vecinos como Valdabín y algún otro; 3 vecinos y medio como Villolquite, o 4 vecinos.

Este vecindario se puede cotejar con otros de la misma época con resultados fiables como tendencia, pero con datos dispares en numerosos pueblos. Se han manejado los vecindarios de todos los puentes reseñados en el trabajo. En cuadro aparte se recoge una muestra para valorar las posibilidades de estos vecindarios. Se ha seleccionado dos comarcas leonesas bien definidas, una parte de Tierra de Campos (las Llanuras Secas) y Los Oteros ${ }^{84}$, añadiendo, finalmente, un brevísimo apunte sobre Frómista. Se estudian 5 repartimientos correspondientes a los años 1691, Benavente; 1692, Frómista; 1693, Lerma; 1694 Quintana del Puente y, 1696 León, por lo que sus resultados no pueden tomarse como una foto fija de la población. La secuencia cronológica permite recoger las oscilaciones de vecinos,

81. Lanza García, R.: «El vecindario...», op. cit., da a León 3.050 vecinos, p. 339.

82. La inclusión de Mayorga, Villabrágima (Valladolid), Becerril y Ampudia (Palencia), no distorsiona el punto de vista general.

83. Vela Santamaría recuerda que los concejos asturianos solicitaron no ser incluidos en los repartimientos de Castilla. La situación es distinta a finales de siglo.

84. Pérez Álvarez, M. a J., Rubio Pérez, L. M.: «Familia y comunidad rural. Modelos agrarios, colectivismo social y comportamientos familiares en la provincia de León durante la Edad Moderna», Studia Historica. Historia Moderna, 36, 2014, p. 180, nota 8.

Ediciones Universidad de Salamanca / 요 Stud. his., H. ${ }^{a}$ mod., 39, n. 2 (2017), pp. 257-291 
pero dado que solo abarca un intervalo de 6 años lo normal es que se refleje una cierta estabilidad dentro de alteraciones mínimas. Difícilmente se podría observar si esas oscilaciones se deben al aumento de nacimientos, de las defunciones o a movimientos migratorios. El repartimiento de León es muy particular comparado con los anteriores, más que las similitudes sorprenden las discontinuidades, con saltos numéricos en muchos casos de 1 a 2 para lo que debe haber alguna explicación que desconozco. No puede obedecer a que los verederos hayan hecho su trabajo con mayor precisión, ni se puede pensar que en los años anteriores hubiera ocultaciones «masivas», ni tampoco sirve acudir a errores de transcripción frecuentes en la toponimia, pero no en las cifras. En resumen, el repartimiento de León constituye un enigma que merecería ser estudiado.

\subsection{Vecinos en Villarta}

En el repartimiento para el puente de Villarta encontramos todo lo contrario. 250 entidades de población con 65.810 vecinos y un promedio de 263 vecinos por pueblo. De mayor a menor hay 39 entidades con 500 o más vecinos (11,6\%). Toledo (2.500), Almagro (1.536), Chinchón (1.100), Daimiel (1.118), Villanueva de los Infantes (1.039) y Alcázar de S. Juan (1.013) ocupan los primeros puestos, seguidos de 3 poblaciones con 900,8 localidades con 800 , de 700 hay 5 , otras 5 de 600 y, finalmente, 12 de 500 vecinos, con un total de 31.087 vecinos, o sea: el $15,6 \%$ de los pueblos reúnen el 47,09\% de la población. En el escalón inferior tan solo cuatro poblaciones con 10 vecinos o menos: Chueca y Ontígola (10), Villar de Cantos (6) y Santiago (4).

En teoría los vecindarios se hacían metódicamente: se enviaban verederos con asignación de las localidades y luego el escribano registraba las cifras, y los días empleados en el trabajo. Ahora bien, los expedientes de Quintana del Puente y de Villarta recogen múltiples fallos que obligan a rectificar el número total de vecinos y, en consecuencia, matizar el valor de estos vecindarios. En Quintana del Puente el primer vecindario da 47.529 vecinos y se comenta: «de que resultó haber de quiebras en él 3.872 vecinos» por incluir lugares exentos o fuera de las 20 leguas. El segundo vecindario da 44.985 vecinos y aún hay que restar otros 892 «por haberse minorado a diferentes villas y lugares su vecindad» ${ }^{85}$. Para el puente de Villarta los verederos fueron dos veces a los mismos pueblos, en 1679 y en 1689 porque se era consciente de la disminución de la vecindad a consecuencias de la peste de 1684. De hecho en 1689 se contabilizan 2. 625 vecinos menos.

85. AHN, RGS, leg. 7.537, Las Grañeras, por ejemplo, contabiliza 6-10 vecinos en otros vecindarios y aquí figura con 40 .

Ediciones Universidad de Salamanca / 뾰 Stud. his., H. ${ }^{a}$ mod., 39, n. 2 (2017), pp. 257-291 
El veredero había anotado para S. Clemente 1.800 vecinos, siendo así que solo tenía 842; Valenzuela contaba con 67 vecinos y aparecía con 100; a Tarancón, 57,5 vecinos, el veredero le había asignado 1.100; a Honrubia, y así otros varios hasta la suma de $2.695^{86}$.

\section{Conclusiones}

Al terminar este repaso de cifras de costos y de actos administrativos a lo largo de años, no se puede reducir sin más el «alivio de los vasallos» a mera fórmula de un lenguaje político estereotipado en boca de los consejeros. Las rebajas en los repartimientos no son un tópico vacío de «larga duración». Se puede cuestionar la magnitud de los resultados, ni espectaculares ni definitivos. Es la fórmula de unos sólidos juristas - los consejeros- que debían su estatus a la gracia real, con independencia de los canales por los que esta se distribuía. En cualquier caso, las cantidades finales de las obras estudiadas son notablemente más bajas que las iniciales, en algunos casos hasta un $40 \%$. Esto es: la obra en sí, se abarataba. «La Corona también fue consciente de aliviar la carga fiscal para estimular el consumo y la inversión», afirma Font de Villanueva, en una apretada síntesis de los logros y limitadas realizaciones durante el reinado de Carlos II, con unos «resultados [...] significativos» ${ }^{87}$. Así pues, «alivio de los vasallos», tal vez más presentido por el Consejo Real que experimentado por los vasallos, enmarcado en un conjunto de medidas renovadoras.

La insistencia en pregonar una y otra vez las obras para lograr rebajas efectivas era uno de los medios del Consejo para proteger las haciendas municipales, la «dote» que el Príncipe concedía a sus vasallos, aunque donde el Consejo mostró más claramente su voluntad, fue en el recorte efectivo de gastos genéricos.

La larga duración de los procesos encarecía las obras. No hay constancia de que los maestros canteros modificaran al alza los presupuestos de materiales y salarios. Ahora bien, el tiempo no es el problema del Consejo de Castilla, sino de los lugares afectados directamente que solicitan el comienzo de las obras en cuanto hay un atisbo de proyecto y presupuesto. Para el Consejo lo primero es proteger los cuerpos que configuran la «República» y sus ordenanzas. Garantizar los derechos de esas entidades, así que, para el Consejo, reparar un puente va mucho más allá de una cuestión de técnicas y presupuestos. Los consejeros aportan solidez jurídica, los maestros canteros arriesgan sus haciendas para aportar la solidez de la obra.

Añadamos un elemento no directamente relacionado con nuestro tema, pero no superfluo. A partir de febrero de 1680 comienza a prepararse una estabilidad

86. AHN, RGS, leg. 7.554, 12 de julio de 1692.

87. Ver nota 4.

Ediciones Universidad de Salamanca / 뾰 Stud. his., H. ${ }^{a}$ mod., 39, n. 2 (2017), pp. 257-291 
monetaria, importante en las grandes cuentas, por supuesto, pero que irá repercutiendo lentamente en el conjunto de la sociedad. Muchas de las deudas que contraían los ayuntamientos se financiaban a crédito y ya antes del decreto de 1704 que baja los tipos de interés del 5 al 3,3\%, los ayuntamientos (no solo ellos, también los nobles y los particulares) obtienen facultad del Consejo de Castilla para renegociar sus préstamos a la baja, generalizándose ya el 3,3\% de interés ${ }^{88}$.

Las bajas protagonizadas por los maestros, favorecida por la política dilatoria del Consejo, parecen jugar contra la solidez de las obras. Los maestros saben que arriesgan sus haciendas y las de sus familiares en un contexto de una fuerte competencia que hubieron de manejar con habilidad: se valían de testaferros, utilizaban el sistema de «prometidos» para eliminar a competidores y aprovechaban los resquicios legales. Nada nuevo. Por ejemplo Moncalián, al que nos hemos referido, pretende retirarse de la obra de los puentes de Lerma cuando el Consejo quiere obligarle a aceptar una propuesta más baja que la suya, alegando que él creía que se trataba de un solo puente frente a los dos objeto de reparación ${ }^{89}$.

Contar vecinos fue una necesidad vital del Consejo, por ello cada puente lleva anexo su vecindario. Los resultados dependían no solo de los comisionados, sino del trabajo metódico realizado por los verederos, aunque no se sabe en cada caso los criterios para contabilizar la población, por ello los datos obtenidos, siendo valiosos, reflejan más las incertidumbres del sistema que la realidad numérica. En último término, los verederos son los ojos con los que el Consejo ve su territorio.

No todo es decadencia y crisis a finales del XviI, no se abandona la actividad constructora, y se cuidan los puentes que permiten el intercambio de personas y mercancías. Subyace una pugna de intereses entre pueblos volcados en la agricultura de subsistencia y villas y ciudades más afectadas por intereses comerciales. El Consejo trata de integrar ambos protagonistas.

Las obras públicas reseñadas, por una parte muestran la capacidad de la administración de controlar el territorio y, por otra, nos ofrecen elementos valiosos

88. AHN, Consejos, libro 1475, 12 de febrero de 1705. Se anula la ley 12, título 15 del libro $5^{\circ}$ de la Nueva Recopilación que establecía un $5 \%$ de interés (20.000 al millar) y lo baja al 3,3\% (33.000 al millar y un tercio). Esta materia ocupa buen número de folios en cualquier protocolo del Archivo Histórico de Protocolos de Madrid a partir de 1690. Sin salirnos del AHN, Palenzuela renegocia con el deán y cabildo de la Iglesia-catedral de Palencia una deuda total de 49.176 reales a un interés de $5 \%$, a cambio de 51.000 reales al 3,3\%, cubriendo los 1.824 reales de más los costos de la operación. AHN, RGS, leg. 7.565, 6 de junio de 1693. Multitud de casos similares. Palenzuela es uno de los lugares afectados por los reparos de puentes sobre el Arlanza. El Registro General del Sello es una fuente de información también en este particular. No se suele tener en cuenta este hecho, pero sería uno más de los elementos que podría aportar Font Villanueva, ver nota 4.

89. AHN, RGS, leg. 7.556, 4 de julio de 1693.

Ediciones Universidad de Salamanca / 뾰 Stud. his., H. ${ }^{a}$ mod., 39, n. 2 (2017), pp. 257-291 
JESÚS BRAVO LOZANO

ALIVIAR A LOS VECINOS: EL CONSEJO DE CASTILLA Y LAS OBRAS PÚBLICAS EN EL REINADO DE CARLOS II. PUENTES Y VECINOS

aunque incompletos para un estudio demográfico. La meseta norte, y en especial el espacio de León, constituyen un valioso banco de pruebas para comprender la complejidad de la administración a finales del s. XviI.

Cuadro 1. Vecinos según repartimientos en Tierra de Campos ${ }^{90}$

\begin{tabular}{|l|c|c|c|c|c|}
\hline & $\begin{array}{c}\text { Benavente } \\
91\end{array}$ & $\begin{array}{c}\text { Frómista } \\
92\end{array}$ & $\begin{array}{c}\text { Lerma } \\
93\end{array}$ & $\begin{array}{c}\text { Q. del } \\
\text { Puente } 94\end{array}$ & $\begin{array}{c}\text { León } \\
96\end{array}$ \\
\hline ALBIRES & 7 & 15 & - & 12 & 28 \\
\hline BERCIANOS & - & 14 & 20 & 10 & 24 \\
\hline CASTROTIERRA & 8 & 10 & - & 12 & 15 \\
\hline CASTRO VEGA & 15 & 13 & - & 17 & $* 26$ \\
\hline GORDALIZA P. & - & 17 & 17 & 15 & 32,5 \\
\hline GRAJALEJO & 6 & 6 & - & - & 15 \\
\hline JUARILLA & 24 & 24 & 16 & 14 & 30 \\
\hline LAS GRAÑRAS & 10 & 5 & - & $6 * *$ & 10 \\
\hline MELGAR de Abajo & 20 & 18 & 25 & 19 & 27,5 \\
\hline S. MIGUEL MONTAÑAN & 11 & 12 & 9 & 10 & 9 \\
\hline STA. CRISTINA & 18 & 20 & - & 14 & 34,5 \\
\hline VALMADRIGAL & & & & & 16 \\
\hline VALLECILLO & 8 & 8 & 8 & 10 & 16 \\
\hline VALVERDE ENRIQUE & 5 & 10 & - & 8 & 9 \\
\hline VILLAMORATIEL & 14 & 12 & - & 10 & 20 \\
\hline VILLAMUNIO & 14 & - & 11 & 11 & 14 \\
\hline VILLEZA & $5 ?$ & $5 ?$ & 6 & 7 & 10,5 \\
\hline YZAGRE & - & 10 & - & 11 & 13 \\
\hline TOTAL & $165 / 68$ & $189 / 98$ & $102 * * *$ & $186 / 85$ & $330,5 / 149,5$ \\
\hline
\end{tabular}

90. Benavente: AHN, RGS, leg. 7.544, 26 de mayo de 1691; Frómista: Idem, leg. 7.559, 26 de noviembre de 1692; Quintana Del Puente: Idem, leg. 7.574, mayo de 1694; Lerma: Ibidem, leg. 7.556, 4 de julio de 1693; LEÓN: Idem, leg. 7.586, 23 de mayo de 1696. * Castrovega y agregado Veguellina. **: En 1690 Las Grañeras figura con 40, leg. 7.537, 18 de abril de 1690, referido a obras anteriores. $* *$ Para Lerma hay que tener en cuenta que solo coinciden siete pueblos con los demás repartimientos (17). En la columna del Total se recogen, pues, dos cantidades separadas por / La segunda cantidad corresponde al repartimiento de Lerma. 
JESÚS BRAVO LOZANO

ALIVIAR A LOS VECINOS: EL CONSEJO DE CASTILLA Y LAS OBRAS PÚBLICAS EN EL REINADO DE CARLOS II. PUENTES Y VECINOS

Cuadro 2. Vecinos de la comarca de Los Oteros ${ }^{91}$

\begin{tabular}{|c|c|c|c|c|}
\hline & $\begin{array}{l}\text { Benavente } \\
91\end{array}$ & $\begin{array}{l}\text { Frómista } \\
\quad 92\end{array}$ & $\begin{array}{l}\text { Quintana P. } \\
\quad 94\end{array}$ & $\begin{array}{l}\text { León } \\
96\end{array}$ \\
\hline ALMONACID & - & 12 & 10 & 18,5 \\
\hline FONTANIL & 5 & 7 & 6 & 10,5 \\
\hline FUENTES & 6 & 9 & 6 & 11 \\
\hline GUSENDOS & 15 & 27 & 18 & 35,5 \\
\hline MATADEÓN & 19 & 7 & 12 & 21 \\
\hline MATALLANA* & 20 & 17 & 25 & $\begin{array}{c}32,5 \\
\text { «de Valmadrigal» }\end{array}$ \\
\hline NAVA & 5 & - & 4 & 4 \\
\hline PAJARES & 16 & 30 & 25 & 38,5 \\
\hline POBLADURA & 3 & 8 & - & - \\
\hline QUINTANILLA & 8 & 11 & 10 & 13,5 \\
\hline REBOLLAR & 10 & 12 & 8 & 22 \\
\hline S. JUSTO & 9 & 9 & 10 & 16,5 \\
\hline S. PEDRO & 6,5 & 9 & 7 & 21 \\
\hline S. ROMÁN & 15 & 12 & - & 32,5 \\
\hline STA. MARÍA & 6 & 8 & 5 & 10 \\
\hline TABARES & 9 & - & - & 13 \\
\hline VELILLA & 8 & 7 & - & 7 \\
\hline OTEROS & - & 8 & - & - \\
\hline TOTAL & 152,5 & 193 & 146 & 307 \\
\hline
\end{tabular}

91. Benavente: AHN, RGS, leg. 7.544, 26 de mayo de 1691; Frómista: Ibidem, leg. 7.559, 26 de noviembre de 1692; QuintANA DEL Puente: Ibidem, leg. 7.574, mayo 1694; León: Ibidem. leg. 7.586, 23 de mayo de 1696. " Matallana se recoge en 3 de estos repartimientos como «de los OTEROs», pero en el de León (1696), se designa claramente como de «Valmadrigal» (como el próximo pueblo de Sta. Cristina).

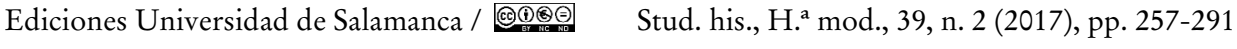


JESÚS BRAVO LOZANO

ALIVIAR A LOS VECINOS: EL CONSEJO DE CASTILLA Y LAS OBRAS PÚBLICAS EN EL REINADO DE CARLOS II. PUENTES Y VECINOS

Cuadro 3. Vecinos Frómista ${ }^{92}$

\begin{tabular}{|c|c|c|c|c|c|}
\hline $\begin{array}{c}\text { Benavente } \\
1691\end{array}$ & $\begin{array}{c}\text { Covarrubias } \\
1692\end{array}$ & $\begin{array}{c}\text { Lerma } \\
1693\end{array}$ & $\begin{array}{c}\text { Trespaderne } \\
1693\end{array}$ & $\begin{array}{c}\text { Quintana P. } \\
1694\end{array}$ & $\begin{array}{c}\text { León } \\
1696\end{array}$ \\
\hline 55 & 94 & 116 & 90 & $118 / 110 *$ & $60 \% *$ \\
\hline
\end{tabular}

\section{Bibliografía}

Alzola Minondo, P.: «Historia de las Obras Públicas en España». Madrid, 2001, 3. a ed. Aramburu-Zabala Higuera, M. Á.: «Todos los caminos conducen a Madrid. Los primeros pasos de la centralización de las comunicaciones españolas», en: Madrid en el contexto de lo hispánico desde la época de los descubrimientos. Madrid, 1994, 2 vols.

Aramburu-Zabala Higuera, M. Á.: «Las obras públicas en la corona de Castilla entre 1575 y 1650: los puentes». Tesis Doctoral. UAM, 1987, Valladolid, 1992.

Aramburu-Zabala Higuera, M. Á.: La Arquitectura de puentes en Castilla y León, 15751650. Valladolid, Junta de Castilla y León, 1992

Aramburu-Zabala Higuera, M. Á.: Fraude y corrupción en la arquitectura del Siglo de Oro. Universidad de Cantabria, 2001.

Bartolomé Bartolomé, J. M.: «Condiciones de vida y privacidad cotidiana del campesinado leonés de Tierra de Campos: La Comarca de Sahagún en el siglo XviII», Estudios Humanísticos, Historia, 3, 2004.

Bustamante García, A.: «Caminos y Palacios. Felipe II entre la capital y El Escorial», en Madrid en el contexto de lo hispánico desde la época de los descubrimientos. Madrid, 1994, 2 vols.

Bustelo García del Real, F.: «El vecindario general de España de 1712-1717 o Censo de Campo Florido (I)», Revista Internacional de Sociología, XXXII:7-8, 1973.

Castillo de Bobadilla, J.: «Política para corregidores y señores de vasallos en tiempo de paz y de guerra y para juezes eclesiásticos y seglares y de Sacas, Aduanas, y de Residencias y sus officiales: y para Regidores, y abogados y del valor de los Corregimientos y Goviernos Realengos y de las Ordenes». Estudio preliminar de Benjamín Hernández. Madrid, 1978. ed. Facsímil, Instituto de Estudios de la Administración local. $2^{a}$ ed. 1992,

Corella SuÁrez, P.: «Puentes y caminos reales en torno a la Corte, siglos XVII y XVIII», en Madrid en el contexto de lo hispánico desde la época de los descubrimientos. Madrid, 1994, 2 vols.

92. Benavente: AHN, RGS, leg. 7544, 26 de mayo de 1691; Covarrubias: Idem, leg. 7.553, 14 de junio de 1692; Lerma: Ibidem, leg. 7.556, 4 de julio de 1693; Trespaderne: Idem, leg. 7.551, 12 de diciembre de 1693; QuinTANA DEL P.: Idem, leg. 7574, mayo 1694; LeÓN: Idem, leg. 7.586, 23 de mayo de 1696. * En 1690 figuran 118; en 1694 los 110. ** En el expediente de Frómista no aparece el número de vecinos de la población, únicamente el dato de que se le asigna doble vecindad. Con el cupo de 8.250 rs. asignados a Frómista calculo 104 vecinos.

Ediciones Universidad de Salamanca / 
Ezquerra Revilla, I.: «Los sitios reales y la continuidad territorial de la Corte. El espacio patrimonial regio y su integración en el entorno», en MARTínez Millán, J. y HorTAL Muñoz, J. E. (coords.): La Corte de Felipe IV (1621-1665). Reconfiguración de la Monarquía Católica. Madrid, Polifemo, 2015, 3 vols.

Ezquerra Revilla, I.: «Jornadas reales, red viaria y espacio cortesano en tiempos de Felipe IV. Las prevenciones camineras del doctor Juan de Quiñones, alcalde de casa y corte», Libros de la Corte.es. 2011.

Fernández Ordóñez, J. A., Abad Balboa, T., Chías Navarro, P.: «Catálogo de puentes anteriores a 1936. LEÓN». Madrid, Colegio de Ingenieros de Caminos, Canales y Puertos. Biblioteca CEHOPU. CEDEX. 1988

LANZA GARCíA, R.: «El vecindario de 1683: una fuente inédita para el estudio de la población de la Corona de Castilla», Revista de Historia Económica, XXIII:2, 2005.

López García, J. M., Equipo Madrid de Estudios Históricos: «El impacto de la Corte en Castilla: Madrid y su territorio en la época moderna». Madrid, Siglo Veintiuno Editores, 1998.

Lucas Villanueva, O.: «El transporte terrestre a través de la cordillera cantábrica en tiempos de Felipe II. Un estudio a partir de la correspondencia de Simón Ruiz con Laredo», Studia Historica. Historia Moderna, 34, 2012.

Marcos Martín, A.: «Hacer Historia desde Simancas», en Homenaje a José Luis Rodríguez de Diego. Valladolid, Junta de Castilla y León, 2011.

Pérez Álvarez, M. J J. y Rubio Pérez, L. M.: «Familias y comunidad rural. Modelos agrario, colectivismo social y comportamientos familiares en la provincia de León durante la Edad Moderna», Studia Historica. Historia Moderna, 36, 2014.

Navascués, P.: «Puentes de acceso al Escorial», Archivo Español de Arte, LVIII, 1985.

Novísima Recopilación de las leyes de España en que se reforma la recopilación publicada por el señor don Felipe II en 1567, reimpresa últimamente en el de 1775 en que se incorporan las pragmáticas, cédulas, decretos y resoluciones reales, y otras providencias no recopiladas, y expedidas hasta el de 1804. Carlos IV Rey de España, Madrid, BOE, 1992.

Pescador del Hoyo, M. C.: «Fraude en el Puente de Toledo, 1673-1680», Anales del Instituto de Estudios Madrileños, Madrid, CSIC, T. 6, 1970.

Sánchez Belén, J. A.: La política fiscal en Castilla durante el reinado de Carlos II. Madrid, S. XXI, 1996.

SÁnchez Belén, J. A.: «Absolutismo y fiscalidad en Castilla a finales del s. XVII: el empadronamiento general del Reino (1682-1685)», Espacio, Tiempo y Forma. Serie IV, Historia Moderna, t. 2, 1989.

Santayana Bustillo, L.: «Gobierno político de los pueblos de España y el corregidor, alcalde y juez en ellos». Estudio preliminar Tomás y VALIENTE, F., Madrid, Instituto de Estudios de la Administración local, 1979.

Tapia García, N.: Técnica y Poder en Castilla durante los siglos XVI y XVII. Salamanca, 1989.

Vela Santamaría, J:: «Las obras públicas en la Castilla del siglo XVII: un gravamen oneroso y desconocido», Studia Historica. Historia Moderna, 32, 2010

Ediciones Universidad de Salamanca / 뾰 Stud. his., H. ${ }^{a}$ mod., 39, n. 2 (2017), pp. 257-291 
JESÚS BRAVO LOZANO

ALIVIAR A LOS VECINOS: EL CONSEJO DE CASTILLA Y LAS OBRAS PÚBLICAS

EN EL REINADO DE CARLOS II. PUENTES Y VECINOS

Vela Santamaría, J.: «Una fuente inédita para la demografía de la Corona de Castilla en el siglo xvir: El Registro General del Sello», en Marcos MarTín, Hacer Historia desde Simancas. Homenaje a José Luis Rodríguez de Diego. Valladolid, Junta de Castilla y León, 2011.

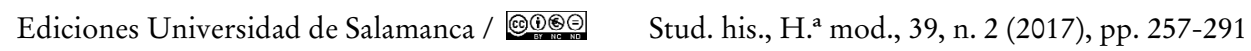


